\title{
Brain mechanisms of visual encoding and working memory in psychometrically identified schizotypal individuals and after acute administration of haloperidol
}

\author{
BRUNO KOPP, ${ }^{\mathrm{a}}$ MONIKA WOLFF, ${ }^{\mathrm{a}}$ CLAUDIA HRUSKA, ${ }^{\mathrm{b}}$ AND FRIEDEL M. REISCHIES ${ }^{\mathrm{c}}$ \\ ${ }^{a}$ Department of Psychology, Humboldt-University, Clinical Psychology and Behavioral Neuroscience, Berlin, Germany \\ ${ }^{\mathrm{b}}$ Max Planck Institute of Cognitive Neuroscience, Leipzig, Germany \\ ${ }^{\mathrm{c}}$ Department of Psychiatry, Free University, Berlin, Germany
}

\begin{abstract}
A probabilistic association task that manipulated the necessity to temporarily store information was combined with the recording of event-related potentials. In Experiment 1, scores obtained from a positive schizotypy scale were used to categorize participants as either low or high schizotypal individuals. Low, but not high, schizotypal individuals displayed evidence for selective associative learning in the working memory dependent ("trace") version of the task. The amplitudes of the occipito-temporal N150 were attenuated in high schizotypal individuals. In Experiment 2, the intravenous administration of a single dose of haloperidol $(0.04 \mathrm{mg} / \mathrm{kg})$, but not of a placebo, strengthened the selectivity of associative learning in the trace version of the task. The amplitudes of the occipito-temporal N150 were augmented by haloperidol. Psychometrically identified schizotypal individuals and normal individuals under mild stress demonstrated defective prioritization of information in working memory and deficient visual encoding. These neurocognitive effects of schizotypy and stress seem to be mediated by the D2 family of dopamine receptors.
\end{abstract}

Descriptors: Schizotypy, Working memory, Visual encoding, Stress, Dopamine, Event-related potential

Bleuler (1911/1950) considered disturbed associative processes as the single most important feature of schizophrenia, and he coined the term Assoziationslockerung (loosening of associations) to describe this defect. In the framework proposed by Meehl (1990), schizophrenia was conceptualized as resulting from interactions between a genetic diathesis and stressful events (see also Benes, 1997; Walker \& DiForio, 1997). According to Meehl, individuals with this diathesis, which he termed "schizotypes," share an inherited brain dysfunction that he believed to affect synaptic transmission. In general agreement with the Bleuler-Meehl model of the schizophrenia spectrum, it has become increasingly apparent that schizophrenia is accompanied by a broad spectrum of cognitive impairments, albeit the debate whether these deficits are generalized or more specific is still ongoing (Chapman \& Chapman, 2001; Strauss, 2001). Chronic schizophrenia, but not schizotypy, is associated with illness-related epiphenomena such as prior psychosis, antipsychotic medication, and hospitalization, so that the performance of schizotypal individuals on cognitive tasks is less likely to be confounded by the often massive deficits in motivation, task comprehension, antipsychotic medication and hospital-

This research was supported by the Deutsche Forschungsgemeinschaft (KO 1239).

Address reprint requests to: Bruno Kopp, Department of Psychology, Humboldt-University, Clinical Psychology and Behavioral Neuroscience, Hausvogteiplatz 5-7, 10117 Berlin, Germany. E-mail: bkopp@rz.hu-berlin.de. ization. It is no surprise, therefore, that whereas schizophrenic patients show marked deficits in most areas of cognitive processing, schizotypal individuals show more circumscribed cognitive deficits (see below).

Disordered cognition in the schizophrenia spectrum may be best studied in tasks that require maintenance of information until it can be used to guide behavior (Goldman-Rakic \& Selemon, 1997). According to these authors, working memory is specifically designed to maintain information until it can be used to guide behavior or be transferred to long-term memory. Baddeley (2000) recently revised Baddeley and Hitch's (1974) widely known threecomponent model of working memory. The revised model still consists of the central executive system, which is supported by modality-specific storage systems such as the visuo-spatial sketch pad and the phonological loop. The visual store itself may have two separable components, one concerned with pattern processing and detecting what (the ventral or occipito-temporal system), whereas the other is concerned with location in space, and conveys information about where (the dorsal or occipito-parietal system; Ungerleider \& Mishkin, 1982). Baddeley (2000) proposed a fourth component to the model, the episodic buffer. It comprises a limited capacity system that provides temporary storage of information, which is capable of binding information from the subsidiary systems, and from long-term memory, into a unitary episodic representation.

Working memory deficits have been repeatedly demonstrated in the schizophrenia spectrum (e.g., Park \& Holzman, 1992; Roit- 
man et al., 2000). Given the multimodal nature of the reported deficits, it is likely that the underlying dysfunction comprises the central executive system of working memory. Others suggested that conceptual visual memory (possibly commensurable with the visuo-spatial sketch pad) is the likely site of core cognitive deficiencies in the schizophrenia spectrum (Knight, 1983, 1994).

A growing body of evidence indicates that event-related brain potential (ERP) components in the 150-200-ms latency range reflect the initial perceptual processing of visual stimulus patterns (Treisman \& Kanwisher, 1998) such as faces, letters, and arabic numerals, and pictures of animals (Hillyard, Teder-Sälejärvi, \& Münte, 1998; Schendan, Ganis, \& Kutas, 1998). In scalp recordings, a negative component peaking at $170-180 \mathrm{~ms}(\mathrm{~N} 170)$ at posterior occipito-temporal sites was found to be much larger in response to pictures of human faces than to pictures of other objects (e.g., Bentin, Allison, Puce, Perez, \& McCarthy, 1996). It has been suggested that this component reflects the initial encoding of facial features rather than recognition of particular faces (e.g., Sommer, Schweinberger, \& Matt, 1991). Paralleling the occipito-temporal N170 is a positive peak over central scalp areas that shows a similar specificity to faces (Jeffreys, 1996). Jeffreys suggested that these components of the ERP are related to aspects of higher visual information processing that are designed to detect very rapidly the suddenly fixated images of familiar objects.

For stimuli other than faces, Schendan et al. (1998) used the labels $\mathrm{N} 150$ and P150 to designate the occipito-temporal and fronto-central peaks, respectively. Because the N150/P150 was elicited selectively by images resembling well-learned categories of visual patterns such as for example words, Schendan et al. suggested that the modulation of this early activity may reflect the cumulative experience people have discriminating between exemplars within categories of visual images. The neural generators of this negative-positive ensemble have been localized by dipole modeling to the posterior inferior occipito-temporal cortex (e.g., Sams, Hietanen, Hari, Ilmoniemi, \& Lounasmaa, 1997).

\section{EXPERIMENT 1}

Experiment 1 examined associative learning, working memory, and visual encoding in psychometrically identified schizotypal individuals (Raine, 1991). Several research groups developed selfreport questionnaires designed to psychometrically identify schizotypal individuals (e.g., Chapman, Chapman, \& Kwapil, 1995; Raine, 1991). Chapman, Chapman, Kwapil, Eckblad, and Zinser (1994) provided initial evidence obtained from a 10-year follow-up study that (a) people reporting schizophrenic-like perceptual distortions and (b) people reporting schizophrenic-like deviant causal beliefs experienced more clinical psychoses than a control group. However, these findings were only partially replicated by Kwapil, Miller, Zinser, Chapman, and Chapman (1997). The pool of psychometrically identified schizotypes includes, but is not limited to, individuals who meet the criteria of the fourth edition of the Diagnostic and Statistical Manual of Mental Disorders (DSM; American Psychiatric Association, 1994) for schizotypal personality disorder (SPD). SPD is a prototypic spectrum disorder that shares common genetic and biological substrates with schizophrenia (Claridge, 1997; Raine, Lencz, \& Mednick, 1995; Siever \& Davis, 1991).

In the probabilistic association task that was described by Kopp and Wolff (2000), participants had to learn associations between visual stimuli that were presented at high temporal frequency. In particular, letters and arabic numbers were used as cues to be associated with symbols that served as outcome stimuli. In the working memory dependent ("trace") version of this task, an interval that lasted longer than 1,000 ms was interposed between the offset of the cues and the onset of the outcome stimulus within each training trial. Because cues and outcome stimuli were necessary elements of a unitary episodic representation, successful performance in this task presupposed maintenance of a neural representation of the cues over the cue-outcome intervals. Because their duration was beyond the duration of immediate and conceptual visual sensory memory (e.g., Knight 1983, 1994), the trace version of the probabilistic association task requires working memory functions, that is, repeated refreshments of the memory traces by rehearsal directed from the central executive system. However, it is easy to obtain a similar, but working-memory-independent ("delayed") version of this probabilistic association task: It is solely necessary to prolong the presentation time of the cues in such a way that the cues and the outcome stimulus coterminate (e.g., Clark \& Squire, 1998). Although the two versions of the probabilistic association task differ with respect to the necessity to temporarily store information, they share all other task characteristics. In particular, they have in common that the contingency of one cue with the outcomes can be manipulated so that the relative validity of another cue (the "target" cue) can be changed, despite maintaining its absolute predictive accuracy. Associative learning is required in both versions of this probabilistic association task because the contingencies between cues and outcomes must be learned. Kopp and Wolff (2000) provided a more detailed discussion of associative learning required in this task. Suffice it to say that in recent years, similarities have been recognized between the fields of Pavlovian conditioning in animals and the acquisition of contingencies in humans, which led to the suggestion that similar processes underlie these two types of learning (Kopp \& Wolff, 2000; Miller \& Matute, 1996; Shanks, Lopez, Darby, \& Dickinson, 1996). In particular, selective learning has been observed in Pavlovian conditioning (Kamin, 1969; Mackintosh, 1975; Rescorla \& Wagner, 1972; Wagner, Logan, Haberlandt, \& Price, 1968) and in judgments of event contingencies in probabilistic association tasks (e.g., Price \& Yates, 1993, 1995). Within the context of probabilistic association tasks, the selectivity of learning refers to the finding that responding (a rating of the extent to which cues and outcomes were related) to the target cue trained in the presence of a valid cue is attenuated to that seen if the target cue had been the only valid stimulus presented with the outcomes (Kopp \& Wolff, 2000; Price \& Yates, 1993, 1995).

This probabilistic association task has been subjected to an ERP analysis by Kopp and Wolff (2000). Both types of cues (letters and arabic numbers) elicited an occipito-temporal N150 with inverted polarity at fronto-central sites (P150). In contrast, the ERPs elicited by the outcome stimuli displayed a broadly distributed positive-going component (P3), peaking at about $400 \mathrm{~ms}$ poststimulus, that was largest over centro-parietal scalp locations. Recently, several studies examined different ERP components that might indicate working memory processes (Luck, Woodman, \& Vogel, 2000). Vogel, Luck, and Shapiro (1998), for example, demonstrated that the P3 can be used as an index for the updating (Donchin \& Coles, 1988) of the central executive system of working memory. Given this, the absence of a $\mathrm{P} 3$ in response to the cues in the probabilistic association task of Kopp and Wolff (2000) can be interpreted as electrophysiological evidence for the existence of an episodic buffer that has been proposed by Baddeley (2000). Moreover, outcome stimuli that violated the individual's expected outcomes elicited an aug- 
mented N2/P3 complex. The error-driven augmentation of the $\mathrm{N} 2 / \mathrm{P} 3$ complex might indicate the operation of adaptive brain systems that allow reaction to unexpected discrepancies (Hillyard \& Picton, 1987). Kopp and Wolff (2000) concluded that learning in the probabilistic association task was driven by the processing of discrepancies between actual and expected outcomes; thus, learning in this task might truly be associative because error correction is a cornerstone of contemporary associative learning rules (e.g., Rescorla \& Wagner, 1972).

Several studies examined the selectivity of associative learning in schizophrenic patients and in schizotypal individuals (Jones, Gray, \& Hemsley, 1990, 1992; Jones, Hemsley, Ball, \& Serra, 1997; Kopp \& Reischies, 2000; Oades, Zimmermann, \& Eggers, 1996). Schizophrenic patients with positive psychotic symptoms showed disturbed selectivity of associative learning (Jones et al., 1992, 1997). Evidence obtained from schizotypal individuals is equivocal (Jones et al., 1990; Oades et al., 1996). Taken together, these studies were interpreted to suggest that disturbed selectivity of associative learning is a state-dependent corollary of psychotic episodes, and by way of the dopamine hypothesis of schizophrenia (Carlsson, 1987), of the hyperactivity in the dopamine system. However, whereas Jones et al. (1997) found disturbed selectivity of associative learning following the administration of the dopamine agonist in healthy subjects, Gray et al. (1997) reported normal selectivity of associative learning after the administration of amphetamine in healthy volunteers. However, selectivity of associative learning was abolished after the administration of amphetamine in rats; in addition, this effect could be reversed by the additional administration of dopamine antagonists (Crider, Solomon, \& McMahon, 1982).

Within the framework of the probabilistic association task (Kopp \& Wolff, 2000), a loss of the selectivity of associative learning should express itself as a loss of attenuated responding to the target cue trained in presence of a valid cue. In fact, chronic schizophrenic patients who were maintained on stable antipsychotic medication showed initial evidence for nonselective learning in this task (Kopp \& Reischies, 2000). The additional demonstration of nonselective learning in the probabilistic association task obtained from psychometrically identified schizotypal individuals would suggest a pathogenetic role of this abnormality because schizotypal individuals are believed to share (some of the) essential neurobiological traits with schizophrenic patients without potential confounds such as antipsychotic medication, hospitalization, and generalized deficit (see above).

So far, we have argued that abnormalities of the central executive system of working memory or abnormalities of the subsidiary visual store(s) might be among the core cognitive deficiencies in the schizophrenia spectrum which-in turnmight be related to clinical symptoms such as associative loosening. Furthermore, we have argued that the N2/P3 complex seems to reflect error correction and updating of the central executive system of working memory, whereas the N150/P150 components of the ERP may be concomitants of the encoding of visual stimuli. Thus, two questions were addressed in the first experiment. First, can evidence for disturbed selectivity of associative learning and/or disturbed working memory functions be provided in psychometrically identified schizotypal individuals? Second, by measuring the N2/P3 complex and the N150/P150 components of the ERP, can evidence for deficient updating of the central executive system of working memory and/or for deficient encoding of visual stimuli be obtained in psychometrically identified schizotypal individuals?

\section{Methods}

\section{Participants}

According to DSM IV (American Psychiatric Association, 1994), schizotypal personality is composed of nine schizotypal traits (Ideas of Reference (IR), Magical Thinking (MT), Unusual Perceptual Experiences (UPE), Paranoid Ideation (PI), Social Anxiety (SA), No Close Friends (NCF), Constricted Affect (CA), Odd Behavior (OB), Odd Speech (OS)). The Schizotypal Personality Questionnaire (SPQ; Raine, 1991) is a 74-item self-report questionnaire closely modeled on DSM criteria for schizotypal personality disorder with established psychometric properties (Raine, 1991; Raine, Reynolds, Lencz, \& Scerbo, 1994). A German translation of the SPQ was used that is nearly identical to the SPQ-G, a published German translation of the SPQ with established validity (Klein, Andresen, \& Jahn, 1997).

Schizotypy is sometimes broken down into three dimensions that are labeled Positive Schizotypy, a trait related to perceptual and cognitive experiences, Negative Schizotypy, a trait related to affective expression and social withdrawal, and Cognitive Disorganization, a trait related to odd behavior. The psychometric identification of schizotypy was solely based on Positive Schizotypy (IR, MT, UPE). Specifically, the $75 \%$ percentile on Positive Schizotypy obtained in the sample of subjects to which the SPQ-G was administered (Table 1) was used as the cutoff criterion for the categorization into low and high psychometrically identified schizotypy. The best differentiation between low and high schizotypy would probably be achieved by using the estimated population base rate of $10 \%$ (Meehl, 1990) as the cutoff criterion. However, the use of such a strict criterion makes it unduly difficult to sample high schizotypal individuals. At the other extreme, a median split would probably lead to the inclusion of too many false positive, "high" schizotypal individuals.

The sample consisted of 619 participants (273 men, age $34 \pm$ 12 years; 346 women, age $33 \pm 12$ years). They were drawn from

Table 1. Nine Schizotypal Traits, SPQ Total Score, Positive Schizotypy Score, Negative Schizotypy Score and Cognitive Disorganization Score Obtained in the Sample of Subjects to which the SPQ-G Was Administered $(N=619)$

\begin{tabular}{lcrrrrr}
\hline \hline Trait & $n$ items & $M$ & $S D$ & $M d n$ & $75 \%$ & $\alpha$ \\
\hline IR & 9 & 2.3 & 2.0 & 2.0 & 4.0 & 0.70 \\
MT & 7 & 2.0 & 2.0 & 1.0 & 3.0 & 0.78 \\
UPE & 9 & 2.1 & 1.9 & 2.0 & 3.0 & 0.69 \\
PI & 8 & 2.2 & 1.8 & 2.0 & 3.0 & 0.67 \\
SA & 8 & 1.9 & 2.0 & 1.0 & 3.0 & 0.75 \\
NCF & 9 & 1.8 & 1.8 & 1.0 & 3.0 & 0.62 \\
CA & 8 & 1.7 & 1.6 & 1.0 & 3.0 & 0.64 \\
OB & 7 & 1.6 & 1.9 & 1.0 & 3.0 & 0.78 \\
OS & 9 & 3.1 & 2.4 & 3.0 & 5.0 & 0.75 \\
Total score & 74 & 18.9 & 11.6 & 17.0 & 26.0 & 0.92 \\
POS $^{\text {a }}$ & 25 & 6.4 & 5.0 & 5.0 & 9.0 & 0.86 \\
NEG $^{\text {b }}$ & 25 & 5.4 & 4.4 & 4.0 & 8.0 & 0.83 \\
CD $^{c}$ & 16 & 4.7 & 3.6 & 4.0 & 7.0 & 0.82 \\
& & & & & & \\
\hline
\end{tabular}

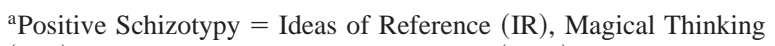
(MT), and Unusual Perceptual Experience (UPE).

${ }^{\mathrm{b}}$ Negative Schizotypy $=$ Social Anxiety (SA), No Close Friends (NCF) and Constricted Affect (CA); (Paranoid Ideas (PI) not included). ${ }^{\mathrm{c}}$ Cognitive Disorganization = Odd Behavior $(\mathrm{OB})$ and Odd Speech (OS). 
the general population $(\mathrm{n}=282)$, from first-year psychology students at Humboldt-University $(\mathrm{n}=93)$, and from the subject register of a pharmaceutical company $(n=244)$. Results obtained from the final sample for the nine schizotypal traits, the three dimensions of schizotypy, and the SPQ total score are presented in Table 1. All participants denied a prior history of psychosis, psychiatric illness, organic brain disease, severe cognitive impairment, or recent drug or alcohol intoxication.

The varimax solution of a PCA on the nine schizotypal traits (specifying three components in advance; Raine et al., 1994) accounted for $69 \%$ of the variance (Table 2). The first component accounted for $44 \%$ of the variance (eigenvalue $=3.9$ ), the second for additional $17 \%$ (eigenvalue $=1.6$ ), the third for $8 \%$ (eigenvalue $=0.7$ ). Four of the SPQ traits had positive loadings on the first component (NCF, CA, SA, PI), measuring Negative Schizotypy. Traits related to psychotic-like cognitive and perceptual experiences (MT, UPE, IR) had positive loadings on the second component, measuring Positive Schizotypy. The third component had positive loadings for $\mathrm{OB}$ and OS, that is Cognitive Disorganization.

From the sample of subjects to which the SPQ-G was administered, 128 participants were finally recruited for participation in Experiment 1. The recruitment was done on the basis of the Positive Schizotypy score, with high schizotypes stemming from the upper quartile and low schizotypes stemming from the remaining quartiles. A particular effort was made to sample low schizotypal individuals from the quartiles below the median in an attempt to improve the differentiation between high and low schizotypy. They gave informed consent after the nature of the study was explained. High schizotypes (32 men, 32 women) were $35 \pm 11$ (mean $\pm \mathrm{SD}$ ) years old, low schizotypes ( 32 men, 32 women) were $32 \pm 10$ years old, $t(126)=1.8$, n.s. Groups did not differ with respect to their scores on the Mehrfachwahl-Wortschatz-Test-B (Multiple-Choice Vocabulary Intelligence Test-B; Lehrl, 1977), a German verbal intelligence scale obtained from 119 subjects, $\mathrm{IQ}_{\mathrm{low}}=$ $119 \pm 13, \mathrm{IQ}_{\text {high }}=118 \pm 20 ; t(117)=-0.5$, n.s., or on the Leistungsprüfsystem 2 (Achievement Measure System 2; Horn, 1983), a German performance intelligence scale obtained from 120 subjects, $\mathrm{IQ}_{\text {low }}=118 \pm 16, \mathrm{IQ}_{\text {high }}=115 \pm 16 ; t(118)=-1.3$, n.s. High schizotypes scored lower than low schizotypes on the Lernund Gedächtnistest 3 (Learning and Memory Test 3; Bäumler,

Table 2. Principal Component Analysis (PCA) of Nine Schizotypal Traits

\begin{tabular}{lccc}
\hline \hline Trait & Component 1 & Component 2 & Component 3 \\
\hline NCF & $\mathbf{. 8 4}$ & .00 & .12 \\
CA & $\mathbf{. 7 9}$ & -.01 & .26 \\
SA & .72 & .26 & .05 \\
PI & .60 & .23 & .37 \\
MT & .06 & .89 & .07 \\
UPE & .12 & .79 & .34 \\
IR & .20 & .63 & .49 \\
OS & .28 & .15 & .79 \\
OB & .14 & .29 & .77 \\
& & & \\
\hline \hline
\end{tabular}

Note: $\mathrm{IR}=$ Ideas of Reference, $\mathrm{MT}=$ Magical Thinking, UPE $=$ Unusual Perceptual Experience, $\mathrm{SA}=$ Social Anxiety, NCF $=$ No Close Friends, $\mathrm{CA}=$ Constricted Affect, $\mathrm{OB}=$ Odd Behavior, $\mathrm{OS}=$ Odd Speech, PI = Paranoid Ideas. Bold entries indicate maximum entry per row.
1974), a paired-associate memory scale obtained from 120 subjects, percent correct $_{\text {low }}=56 \pm 19 \%$, percent correct $_{\text {high }}=47 \pm$ $17 \% ; t(118)=-2.7, p<.05$. The mean handedness score (Oldfield, 1971) did not differ between high and low schizotypes, handedness $_{\text {low }}=63 \pm 46$, handedness high $_{\text {hi }}=68 \pm 41 ; t(126)=0.6$, n.s. All participants reported normal or corrected-to-normal vision. All participants underwent the structured clinical diagnostic interview (SCID; German adaptation; Wittchen, Zaudig, \& Fydrich, 1997) to screen them for Axis I disorders. Participants were paid for participation (DM 50).

Table 3 contains the schizotypy trait scores, the SPQ total score, and the schizotypy component scores of the low (left panel) and high (right panel) schizotypal participants. High schizotypes (33.7/74) generally responded to the SPQ items in a more affirmative manner than did low schizotypes $(10.9 / 74)$. Of particular importance, whereas high schizotypes affirmed $60 \%$ of the items measuring Positive Schizotypy, low schizotypes affirmed less than $10 \%$ of these items. Sixty-four participants (32 high schizotypes [16 men, 16 women], 32 low schizotypes [16 men, 16 women]) were randomly allocated to the trace version or the delayed version of the probabilistic association task. These versions will be described in more detail below.

\section{Stimuli and Procedure}

Information about the contingencies between various stimuli was given in a series of training trials. Participants learned to predict which one of two alternative outcomes would occur on the basis of two cues bearing certain predictive relationships to the outcomes. Simple symbolic stimuli like letters and numbers were used as predictive cues. In addition, arbitrarily chosen symbolic stimuli were used as outcomes. Participants learned to predict an outcome based on the particular combination of predictive cues within a training trial. The data of primary interest were the contingency ratings obtained after a number of training trials.

Table 3. Schizotypy Trait Scores of the Low (Left Panel) and High (Right Panel) Schizotypal Individuals

\begin{tabular}{|c|c|c|c|c|c|c|}
\hline \multirow[b]{2}{*}{ Trait } & \multicolumn{3}{|c|}{ Low schizotypes $(n=64)$} & \multicolumn{3}{|c|}{ High schizotypes $(n=64)$} \\
\hline & $n$ items & $M$ & $S D$ & $M$ & $S D$ & $t(126)$ \\
\hline IR & 9 & 1.0 & 1.5 & 4.5 & 2.3 & $10.3^{*}$ \\
\hline MT & 7 & 0.7 & 1.3 & 5.5 & 2.1 & $15.9 *$ \\
\hline UPE & 9 & 0.8 & 1.1 & 5.1 & 2.0 & $14.7 *$ \\
\hline PI & 8 & 1.3 & 1.6 & 3.0 & 2.1 & $5.2 *$ \\
\hline $\mathrm{SA}$ & 8 & 1.1 & 1.3 & 2.7 & 2.6 & $4.4 *$ \\
\hline NCF & 9 & 1.4 & 1.3 & 2.5 & 2.0 & $3.8 *$ \\
\hline $\mathrm{CA}$ & 8 & 1.3 & 1.4 & 2.4 & 2.0 & $3.8 *$ \\
\hline $\mathrm{OB}$ & 7 & 1.1 & 1.8 & 3.3 & 2.5 & $5.7 *$ \\
\hline OS & 9 & 2.3 & 2.1 & 4.6 & 2.6 & $5.5^{*}$ \\
\hline Total & 74 & 10.9 & 8.6 & 33.7 & 12.7 & $11.9 *$ \\
\hline $\operatorname{POS}^{\mathrm{a}}$ & 25 & 2.4 & 2.9 & 15.0 & 4.7 & $18.2 *$ \\
\hline $\mathrm{NEG}^{\mathrm{b}}$ & 25 & 3.8 & 3.3 & 7.7 & 5.4 & $4.9 *$ \\
\hline $\mathrm{CD}^{\mathrm{c}}$ & 16 & 3.4 & 3.3 & 7.9 & 4.3 & $6.6^{*}$ \\
\hline
\end{tabular}

apositive Schizotypy = Ideas of Reference (IR), Magical Thinking (MT) and Unusual Perceptual Experience (UPE).

${ }^{\mathrm{b}}$ Negative Schizotypy = Social Anxiety (SA), No Close Friends (NCF) and Constricted Affect (CA).

${ }^{\mathrm{c}}$ Cognitive Disorganization $=$ Odd Behavior $(\mathrm{OB})$ and Odd Speech (OS); Paranoid Ideas (PI) not included.

$* p<.01$. 
The experiment was divided into six training blocks (three high validity blocks and three low validity blocks), each consisting of 80 learning episodes obeying the contingencies as specified in Table 4. For example, the conditional probability for the outcome to be at level 1 given a cue 1 at level 1 amounted to $36 / 40=0.9$ in the high $(20 / 40=0.5$ in the low $)$ cue 1 validity condition. At the same time, the conditional probability for the outcome to be at level 1 given a cue2 (which is equivalent to the target cue with constant absolute validity, but manipulated relative validity) at level 1 , amounted to $28 / 40=0.7$ in both validity conditions. Note that the unconditional probabilities $\mathrm{P}\left(\right.$ outcome $\left._{\mathrm{x}}\right), \mathrm{P}\left(\right.$ cue $\left._{\mathrm{x}}\right)$, and $\mathrm{P}\left(\mathrm{cue} 2_{\mathrm{x}}\right)$ were held constant across the validity conditions at 0.5 , with the subscript $\mathrm{x}$ denoting 1 or 2 . Likewise, the conditional probabilities $\mathrm{P}\left(\operatorname{cue}_{\mathrm{x}} / \mathrm{cue}_{\mathrm{x}}\right)$ and $\mathrm{P}\left(\mathrm{cue}_{3-\mathrm{x}} / \mathrm{cue} 2_{\mathrm{x}}\right)$ were equal at 0.7 and 0.3 in both validity conditions, respectively.

The validity condition was held constant during three subsequent blocks. The succession of high and low cue 1 validity was counterbalanced across subjects. Throughout all blocks, two symbols served as outcomes (outcome ${ }_{1}=\#$, outcome ou $_{2}=*$ ), counterbalanced across participants. The cues consisted of letters (cue1) and numbers (cue2). For example, during the first block of trials, cue $1_{1}$ consisted of the letter $\mathrm{A}$, cue $1_{2}$ the letter B; cue $2_{1}$ corresponded to the number 0 , and cue $2_{2}$ to the number 1 . The next block of trials employed the two subsequent letters and numbers (i.e., C, D, 2, and 3) as cue $1_{\mathrm{x}}$ and $\mathrm{cue} 2_{\mathrm{x}}$, respectively. This was repeated until in the last block, $\mathrm{K}$ and $\mathrm{L}$ served as cue $1_{\mathrm{x}}$ and 10 and 11 served as cue $2_{\mathrm{x}}$. The succession of trials within a block was randomized.

In the trace version of the probabilistic association task, a training trial (Figure 1) started with the presentation of a fixation cross in the middle of the screen for half a second. It was followed by the first cue and the second cue (each lasting $250 \mathrm{~ms}$ ) separated by $1 \mathrm{~s}$. The presentation order of cue 1 and cue 2 was counterbalanced across participants. After presentation of the cues, the trialby-trial prediction was carried out by pressing one of two response keys labeled \# (left index finger) and $\infty$ (right index finger). The outcome stimulus was presented $1 \mathrm{~s}$ after the prediction response. The interval between two successive trials was $2 \mathrm{~s}$. All stimuli were presented at the center of a computer screen; gray figures against a black background (height of cues: $3 \mathrm{~cm}$, height of outcome stimuli: $1.5 \mathrm{~cm}$ ).

A training trial in the delayed version of the probabilistic association task did not differ from a training trial in the trace

Table 4. Experimental Design ${ }^{a}$

\begin{tabular}{|c|c|c|c|c|}
\hline \multirow[b]{2}{*}{ Outcome } & \multicolumn{4}{|c|}{ Cues } \\
\hline & $\begin{array}{l}\text { cue }_{1} \\
\text { cue } 2_{1}\end{array}$ & $\begin{array}{l}\text { cue }_{1} \\
\text { cue }_{2}\end{array}$ & $\begin{array}{l}\text { cue } 1_{2} \\
\text { cue } 2_{1}\end{array}$ & $\begin{array}{l}\text { cue }_{2} \\
\text { cue } 2_{2}\end{array}$ \\
\hline \multicolumn{5}{|c|}{ High validity condition } \\
\hline outcome $_{1}$ & 26 & 10 & 2 & 2 \\
\hline outcome $_{2}$ & 2 & 2 & 10 & 26 \\
\hline \multicolumn{5}{|c|}{ Low validity condition } \\
\hline outcome $_{1}$ & 18 & 2 & 10 & 10 \\
\hline outcome $_{2}$ & 10 & 10 & 2 & 18 \\
\hline
\end{tabular}

${ }^{a}$ Number of occurrences of event combinations within one training trial (cue1, cue2, outcome) for blocks of 80 training trials for the high cue1 validity condition and the low cue 1 validity condition. See text for details.

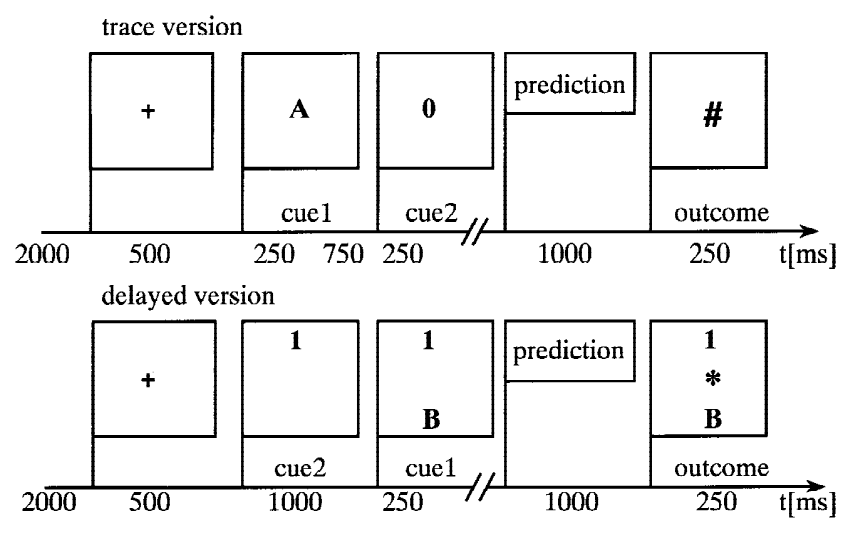

Figure 1. Design of experiment. Upper panel: Trace version of the probabilistic association task. In this trial, the cue 1 is the letter A and the cue 2 is the number 0; the outcome of the trial is \#. Lower panel: Delayed version of the probabilistic association task. In this trial, the cue 1 is the letter B and the cue 2 is the number 1 ; the outcome of the trial is $*$. See text for details.

version of the task, with the sole exception that the cues remained on the screen until the outcome stimulus terminated. To allow for the simultaneous presentation of three stimuli (two cues and one outcome stimulus), the cues were displaced $5 \mathrm{~cm}$ above or below the center of the screen.

After each block of trials, subjects judged eight conditional probabilities, that is, all $\mathrm{P}\left(\right.$ outcome $_{\mathrm{x}} /$ cue $\left._{\mathrm{x}}\right)$ and $\mathrm{P}\left(\right.$ outcome $_{\mathrm{x}} /$ cue $2_{\mathrm{x}}$ ). These ratings were prompted by questions that read as follows:

"If cue $_{\mathrm{x}}$ was present, how probable followed:

outcome $_{1}$ ?

outcome $_{2}$ ?"

From these ratings, contingency judgments were calculated for each participant by calculating the mean rating ((outcome ${ }_{1} /$ cue $\left._{1}\right)+\left(\right.$ outcome $_{2} /$ cue $\left.\left._{2}\right)\right) / 2$ for both cues separately (cue1, cue2).

The experiment began with a practice block consisting of 40 trials employing the letters $\mathrm{X}$ and $\mathrm{Y}$ and the numbers 18 and 19 . After the practice block, participants gave eight probability estimates to familiarize them with the judgment task.

\section{Electrophysiological Recording}

Due to capacity limitations, the electroencephalogram (EEG) was recorded solely from those 64 participants that performed the trace version of the probabilistic association task. The participants sat in a comfortable chair, $1 \mathrm{~m}$ from the screen, in a darkened room. The EEG was continuously recorded according to the International 10-20 system using Zn electrodes mounted on an ECI cap. The EEG was amplified by a 32-channel SYNAMPS amplifier. Linked mastoids served as reference. The EEG was DC recorded and low-pass filtered at a cutoff frequency of $100 \mathrm{~Hz}$. The EEG was digitized on line at a sampling rate of $250 \mathrm{~Hz}$. Electrode impedance was kept below $5 \mathrm{k} \Omega$. Vertical and horizontal electrooculogram (EOG) was recorded from above and below the left eye and from $1 \mathrm{~cm}$ external to the outer canthus of each eye.

\section{ERP Analysis}

The continuous EEG was cut into epochs of 1,200 ms duration. The epochs were time locked to the onset of stimuli, starting 
$200 \mathrm{~ms}$ before and ending 1,000 ms after their onset. EEG epochs were baseline corrected with the interval starting at $50 \mathrm{~ms}$ and ending at the time of the onset of the stimuli. Trials containing horizontal eye movements were rejected; trials containing blinks were corrected using the regression method described by Berg (1986).

The data of primary interest were the ERP waveforms elicited by cues and outcomes during training. The amplitude of the P150 (evoked by the cues) was determined as the maximum voltage level within the poststimulus time window 150-300 ms at Fz. The amplitude of the N150 (evoked by the cues) was determined as the minimum voltage level within the poststimulus time window 150 $300 \mathrm{~ms}$ at $\mathrm{O} 1, \mathrm{O} 2, \mathrm{~T} 5$, and $\mathrm{T} 6$.

ERP waveforms elicited by the outcomes were analyzed in the following manner: N2 amplitude was determined as the mean amplitude within the poststimulus time window 240-340 ms at Fz, $\mathrm{Cz}$, and Pz. The P3 amplitude with its known parietal topography was determined as the mean amplitude within the poststimulus time window 500-700 ms at Pz. Due to excessive artifacts, the ERP data of one high schizotypal person had to be excluded from further analysis.

\section{Results}

\section{Contingency Judgments}

The contingency judgments that were obtained after three blocks of training in each version of the probabilistic association task (trace, delayed) and in each validity condition (low, high cue 1 validity) were analyzed. A 2 (Schizotypy) $\times 2$ (Task Version) $\times 2$ (Cue1 Validity) ANOVA was computed using the cue1 contingency ratings. A significant main effect of cue1 validity emerged, $F(1,124)=174.6, p<.05$, and no other effects were significant except the main effect of group, $F(1,124)=4.3, p<.05$. Thus, the cue1 contingency ratings of both subject groups reflected the validity manipulation, but did not differ between the two task versions. High schizotypes showed a tendency towards somewhat lower contingency ratings than low schizotypes.

Next, a 2 (Schizotypy) $\times 2$ (Task Version) $\times 2$ (Cue1 Validity) ANOVA was computed using the cue 2 contingency ratings. A differential cue interaction effect was confirmed by a significant Schizotypy $\times$ Version $\times$ Validity interaction effect, $F(1,124)=$ $4.4, p<.05$, and no other effects were significant. Two 2 (Schizotypy) $\times 2$ (Cue1 Validity) ANOVAs were specified to test separately for differential cue interaction in low and high schizotypes in the two versions of the probabilistic association task. The Schizotypy $\times$ Validity interaction was not significant in the delayed version of the task (Figure 2, right panel), $F(1,62)=0.0$, n.s. However, the Schizotypy $\times$ Validity interaction was significant in the trace version of the task (Figure 2, left panel), $F(1,62)=7.8$, $p<.05$, confirming that a differential cue interaction effect occurred solely in the trace version of the task. In this task version, the group difference was significant in the low validity condition, $t(62)=-2.1, p<.05$, low schizotypes $>$ high schizotypes, and it approached significance in the high validity condition, $t(62)=$ $2.0, p=.05$, low schizotypes $<$ high schizotypes, implying that the differences between groups are in opposite directions in the two validity conditions. This pattern of results obtained in the trace version of the probabilistic association task is one of the rare examples of double dissociations in psychopathology research (Strauss, 2001). In particular, the cue 2 contingency ratings of the low schizotypal individuals showed the expected cue competition effect: After completion of training, the cue 2 contingency rating
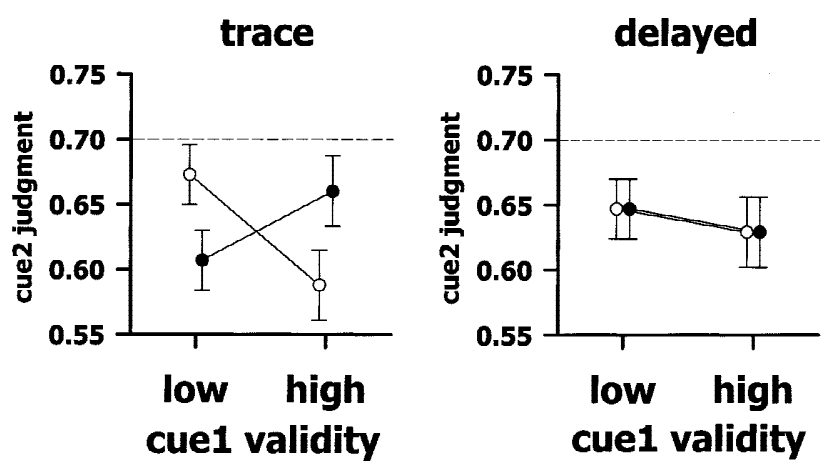

Figure 2. Mean contingency judgments for cue2 as a function of the validity of cue 1 obtained in Experiment 1 after completion of training in low (open symbols) and high (filled symbols) schizotypal individuals. Left panel: Trace version of the probabilistic association task. Right panel: Delayed version of the task.

for the low cue 1 validity condition exceeds that for the high cue 1 validity condition. This finding replicates our earlier findings obtained in two samples of university students (Kopp \& Wolff, 2000). The opposite effect occurred in high schizotypal individuals: After completion of training, the cue 2 contingency rating for the high cue 1 validity condition exceeded that for the low cue 1 validity condition, reflecting a cue cooperation effect. This double dissociation occurred solely in the working memory dependent task version.

\section{Cue ERPs}

Both types of cues (letters, numbers) elicited a broadly distributed frontal P150 with inverted polarity at occipito-temporal sites (N150). Figure 3 shows grand-average ERP waveforms elicited by cue1, separated for low (thin lines) and high (thick lines) schizotypes. The N150 at occipito-temporal electrodes obtained in response to cue1 (letters) peaked at a latency of $166 \mathrm{~ms}$ with a mean amplitude of $-4.3 \mu \mathrm{V}$. An ANOVA (Schizotypy $\times$ Validity $\times$ Site $\times$ Hemisphere) confirmed a significant schizotypy effect for the N150 amplitude, $F(1,61)=4.4, p<.05$, and the N150 latency, $F(1,61)=$ $4.5, p<.05$. No other main or interaction effect reached significance: amplitude: all $F$ 's $(1,61)<2.4$; latency: all $F$ 's $(1,61)<3.6$, except for latency: hemisphere, $F(1,61)=7.2, p<.05$, and for amplitude: site, $F(1,61)=8.8, p<.05$; Schizotypy $\times$ Hemisphere, $F(1,61)=6.7, p<.05$. Post hoc comparisons at the two temporal sites (T5, T6) revealed that the attenuation of the N150 amplitude in high schizotypes was confined to the right hemisphere, $t(61)=-3.0, p<.05$, with no significant attenuation in the left hemisphere, $t(61)=-1.0$, n.s. The frontal P150 peaked at a latency of $186 \mathrm{~ms}$ with an amplitude of $7.0 \mu \mathrm{V}$. Neither the P150 amplitude nor the P150 latency was influenced by schizotypy, validity, or the interaction Schizotypy $\times$ Validity, amplitude: all $F$ 's $(1,61)<1.9$, latency: all $F$ 's $(1,61)<3.8$.

A very similar pattern of results emerged for the ERPs elicited by cue 2 (numbers). The N150 at the preselected occipito-temporal electrodes peaked at a latency of $169 \mathrm{~ms}$ with a mean amplitude of $-5.5 \mu \mathrm{V}$. An ANOVA (Schizotypy $\times$ Validity $\times$ Site $\times$ Hemisphere) confirmed a significant schizotypy effect for the N150 amplitude, $F(1,61)=4.2, p<.05$. No other main or interaction effect reached significance, amplitude: all $F$ 's $(1,61)<3.2$, latency: all $F$ 's $(1,61)<2.5$, except for latency: site, $F(1,61)=7.6$, $p<.05$, and amplitude: site, $F(1,61)=23.0, p<.05$. Although 

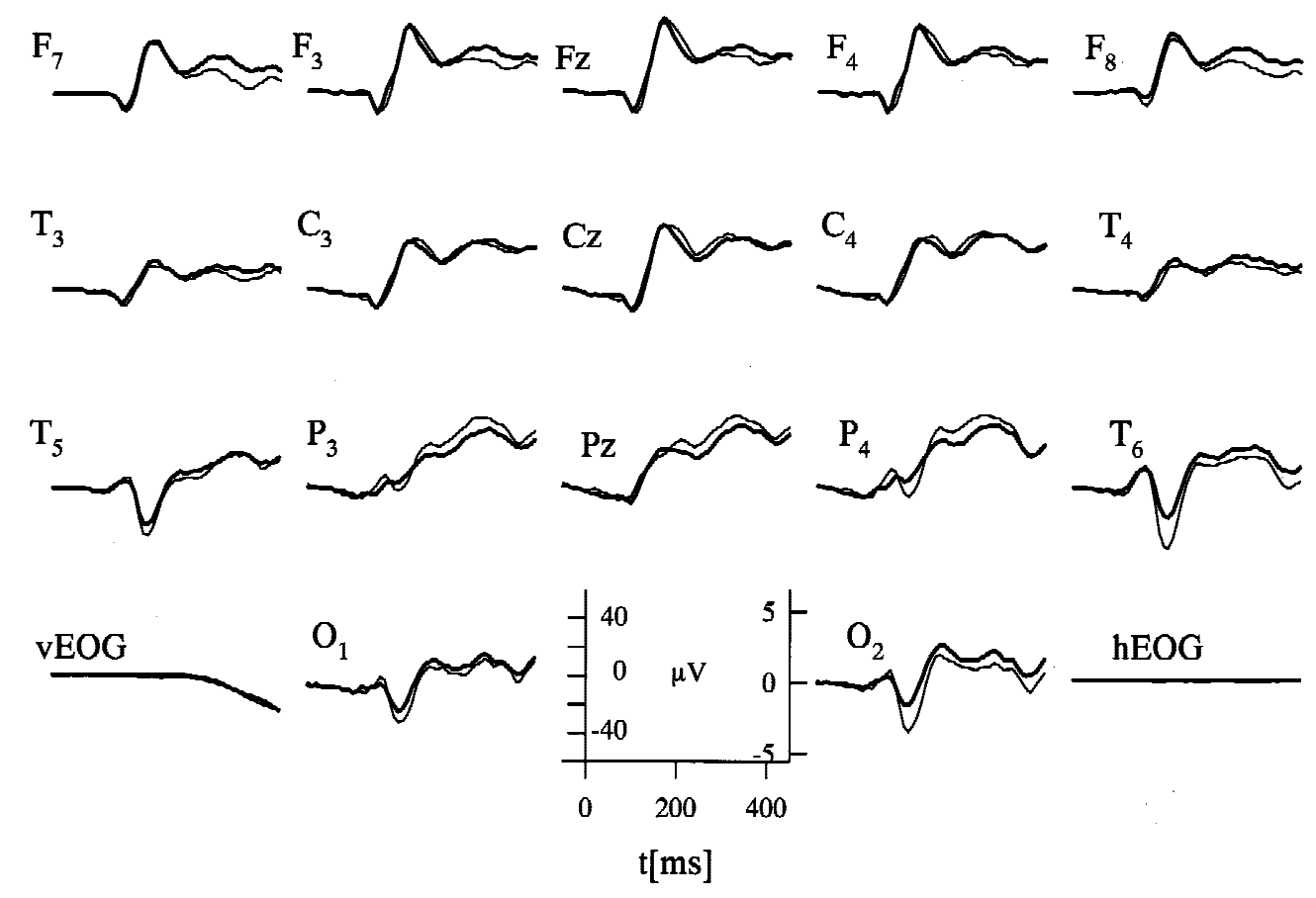

Figure 3. Grand-average ERPs elicited by cue 1 (letter) from -50 to $400 \mathrm{~ms}$, averaged across both validity conditions. Thin (thick) line: ERPs recorded from low (high) schizotypes. Fz, Cz, and Pz refer to midline frontal, central, and parietal sites, respectively. F3, C3, P3, T5, and O1 refer to left frontal, central, parietal, temporal, and occipital sites, respectively. F4, C4, P4, T6, andO2 refer to right frontal, central, parietal, temporal and occipital sites, respectively.

the Schizotypy $\times$ Hemisphere interaction did not reach statistical significance, $t$ tests revealed that the attenuation of the N150 amplitude in high schizotypes was confined to the right hemisphere, $t(61)=-2.2, p<.05$, with no significant attenuation in the left hemisphere, $t(61)=-1.6$, n.s. The frontal P150 peaked at a latency of $189 \mathrm{~ms}$ with an amplitude of $6.0 \mu \mathrm{V}$. Neither the P150 amplitude nor the P150 latency was influenced by schizotypy, validity, or the interaction Schizotypy $\times$ Validity, amplitude: all $F^{\prime}$ 's $(1,61)<0.3$, latency: all $F$ 's $(1,61)<0.6$.

\section{Outcome ERPs}

In general, the ERPs elicited by the outcomes (Figure 4) were very similar to those reported by Kopp and Wolff (2000) in an independent sample of university students. A broad positive-going component occurred, peaking at about $400 \mathrm{~ms}$ poststimulus that was largest over centro-parietal scalp locations. In the high validity condition, correct outcome predictions were much more probable than incorrect outcome predictions (around 25\% incorrect predictions). To prevent a possible confound between the probability of being correct and the true effect of correctness of the outcome prediction on the waveforms (cf. Kopp \& Wolff, 2000), the ERP analysis was restricted to the low validity condition where correct and incorrect outcome predictions occurred with roughly equal probabilities (around 45\% incorrect predictions).

The N2/P3 complex evoked by the outcomes were, by and large, identical in high and low schizotypes (Figure 4). For the N2, an ANOVA (Schizotypy $\times$ Correctness $\times$ Site $)$ was performed. Correctness, $F(1,61)=15.8, p<.05$, and site, $F(2,122)=52.4$, $p<.05, \epsilon=.76$, proved significant, as did the interaction Correctness $\times$ Site, $F(2,122)=5.5, p<.05, \epsilon=.68$. The interaction Schizotypy $\times$ Correctness reached significance, $F(1,61)=4.1$, $p<.05$. High schizotypes displayed a somewhat larger effect of expectancy disconfirmation on the ERP waveforms in the time range of the $\mathrm{N} 2$ than low schizotypes. The remaining effects involving schizotypy were not significant, all $F$ 's $<3.5$. Correctness influenced the P3 significantly, $F(1,61)=58.1, p<.05$. Schizotypy or any interaction involving schizotypy did not reach significance, all $F$ 's $(1,61)<1.1$.

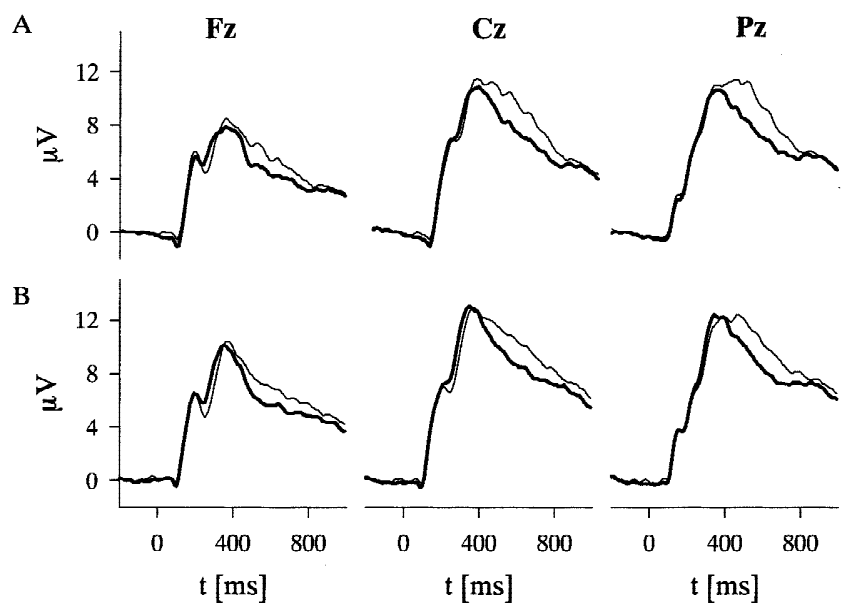

Figure 4. Grand-average ERPs elicited by outcome stimuli from -100 to $1,000 \mathrm{~ms}$ obtained from the low validity condition. (a) ERPs recorded from low schizotypes. (b) ERPs recorded from high schizotypes. Thin (thick) line: ERPs recorded from outcome stimuli that disconfirmed (confirmed) the outcome expectation. $\mathrm{Fz}, \mathrm{Cz}$, and $\mathrm{Pz}$ refer to midline frontal, central, and parietal sites, respectively. 


\section{Discussion}

Associative learning, working memory, and visual encoding were examined in psychometrically identified schizotypal individuals in Experiment 1. Evidence for disturbed selectivity of associative learning in psychometrically identified schizotypal individuals was found in the probabilistic association task, conditional upon the task being working memory dependent. Whereas the N2/P3 complex-putatively indicating error correction and updating of the central executive system of working memory-was unaffected in psychometrically identified schizotypal individuals, the N150, but not the P150, component of the ERP was attenuated particularly over the right hemisphere in these individuals in the workingmemory-dependent trace version of the probabilistic association task. Thus, whereas updating of the central executive system of working memory seems to be unaffected, encoding of visual stimuli into the visual and/or episodic buffer seems to be deficient in psychometrically identified schizotypal individuals.

The relative validity of the target cue (cue2) was the key variable that was changed from the low cue 1 validity condition to the high cue 1 validity condition. In the high validity condition in comparison to the low validity condition, the target cue lost its associative differential, despite maintaining its predictive accuracy. After completion of training, low schizotypal individuals gave lower ratings of the predictive validity of the moderately valid target cue if cue 1 had high validity as compared to low validity. This pattern of contingency judgments indicates competitive interaction between the cues. Thus, selective associative learning was obtained from low schizotypal individuals, similar to the results obtained from university students (Kopp \& Wolff, 2000). In contrast, high schizotypal individuals gave higher ratings of the predictive validity of the moderately valid target cue if cue 1 had high validity as compared to low validity. This pattern of contingency judgments indicates cooperative interaction between the cues and nonselective associative learning, resembling the results obtained from chronic schizophrenic patients (Kopp \& Reischies, 2000).

The differential cue interaction effect cannot be attributed to generalized deficit although Group $\times$ Task interactions are evidence of a specific cognitive impairment only under particular conditions (Strauss, 2001). One of these is double dissociations, which are very unusual in psychopathology research. However, the differential cue interaction effect is an example of a double dissociation. This implies that generalized deficit (e.g., deficient general intelligence or problem-solving capacity, deficient associative learning capacity as assessed in a paired-associate memory test, deficient ability to sustain attention, generally lower task motivation or comprehension) can be ruled out as an explanation for the differential cue interaction effect. Furthermore, the differential cue interaction effect is strictly process specific in the sense that it did occur solely in the working-memory-dependent trace version of the probabilistic association task. Finally, the nosological specificity of the differential cue interaction effect is a critical issue that requires additional research, namely to examine the other Cluster A (i.e., the schizoid and paranoid personality disorders) and the Cluster B and the Cluster C personality disorders.

Perry et al. (2001) recently suggested distinguishing between working memory tasks that require storage and retrieval of information and working memory tasks that in addition to these processes require the manipulation and modification of information that is thought to be performed by the central executive system (Baddeley, 2000). Selective attention might be among the most important processes performed by the central executive system, but little is yet known about the relationship between working memory and selective attention. Only recently, interactions (de Fockert, Rees, Frith, \& Lavie, 2001; Downing, 2000) and overlapping mechanisms (Awh \& Jonides, 2001; McElree, 2001) have been demonstrated. When the particular working memory task requires predicting an outcome on the basis of cues, more valid or more salient cues normally detract from less valid or less salient cues (Kruschke \& Johansen, 1999). Given the evidence presented above, this preferential processing or prioritization (de Fockert et al., 2001) of relevant or predictive information in working memory seems to be specifically disturbed in psychometrically identified schizotypal individuals. The general discussion provides a more detailed discussion of what we would like to call prioritization of predictive information in working memory.

In addition to defective prioritization in working memory, psychometrically identified schizotypal individuals displayed a specific reduction of the occipito-temporal N150, particularly over the right hemisphere, but not of the fronto-central P150 in response to the cues while performing the working-memory-dependent trace version of the probabilistic association task. However, the lateralization of these modulation effects may be dependent upon the exact nature of the applied stimulus materials. The N150 attenuation suggests specific abnormalities in higher visual information processing, namely disturbed initial encoding and/or disturbed rehearsal of visual stimuli into the visual and/or episodic buffer. This interpretation is compatible with other neurophysiological evidence for transient deficits of sensory memory systems in schizophrenic patients (e.g., Bruder et al., 1998; Javitt, Strous, Grochowski, Ritter, \& Cowan, 1997). One negative finding that was obtained from subjects at risk for psychopathology - particularly those showing negative symptoms (Fernandes et al., 1999) suggests that these abnormalities of higher visual information processing might be specifically related to the schizophrenic-like perceptual distortions and schizophrenic-like deviant causal beliefs reported by the psychometrically identified schizotypal individuals who were studied in this experiment. Furthermore, the encoding interpretation of the attenuated N150 is compatible with most analyses of memory deficits in schizophrenic patients. The bulk of these studies suggests that retention and retrieval is normal if the initial encoding of the to-be-remembered information is equated (e.g., Brebion, Amador, Smith, \& Gorman, 1997; Gold et al., 2000).

\section{EXPERIMENT 2}

The neurotransmitter dopamine has played a key role in neurobiological hypotheses about schizophrenia (e.g., Carlsson, 1987). The dopamine hypothesis of schizophrenia arose from observations that the only consistent feature among the antipsychotic drugs used to treat the disease was their ability to antagonize D2 dopamine receptors. In its simplest form, the dopamine hypothesis of schizophrenia states that the psychotic symptoms of the disease may be related to a relative excess of dopamine activity. Moreover, the dopamine system seems to be associated with higher order cognitive processes such as working memory (Braver, Barch, \& Cohen, 1999; Coull, 1998). During the last decade, a preferential modulation of working memory performance via cortical (mainly prefrontal) D1, but not D2, dopamine receptors became apparent in monkeys (Sawaguchi \& Goldman-Rakic, 1991) and in humans (Müller, von Cramon, \& Pollmann, 1998). In sum, although the ability to antagonize D2 dopamine receptors may be an essential 
mechanism of action of antipsychotic agents, the blockade of D1 dopamine receptors may disturb working memory performance. The role of D2 dopamine receptors for working memory still need to be elucidated.

The evidence is accumulating to indicate that the schizophrenia spectrum is characterized by working memory deficits (see above). Given the results obtained in Experiment 1, a specific function of working memory, namely prioritization of predictive information, may be a particular important neurocognitive defect in the schizophrenia spectrum. It is thus tempting to speculate that cortical D2 dopamine receptors might modulate the prioritization of predictive information in working memory. Optimal prioritization in working memory may occur within a normal range of cortical D2 receptor activation. Conditions like schizophrenia (Abi-Dargham et al., 2000; Seeman \& Kapur, 2000), schizotypy (Siever et al., 1991), or stress (Arnsten, 2000) may all be linked to an excess stimulation of cortical D2 dopamine receptors. These hypothetical suggestions lead to the prediction that one essential neurocognitive mechanism of action of D2 receptor antagonists might be to improve prioritization in working memory.

A typical antipsychotic agent is haloperidol, which mainly, though not selectively, antagonizes D2 dopamine receptors (Peroutka \& Snyder, 1980). Therefore, the neurocognitive effects of the blockade of D2 dopamine receptors were examined by administering a single dose of haloperidol to healthy participants who performed the working-memory-dependent trace version of the probabilistic association task that was described above. The essential prediction was that haloperidol-by way of antagonizing D2 dopamine receptors-would possibly optimize prioritization in working memory. Given the correlation between prioritization in working memory and the amplitude of the occipito-temporal N150, a further expectation was that haloperidol would possibly augment the N150 amplitude.

\section{Methods}

\section{Participants}

Twenty-four healthy male volunteers $(34.2 \pm 10.5$ years $)$ were recruited by advertisements in local newspapers. Volunteers were randomly assigned to either of two experimental groups, those receiving haloperidol $(0.04 \mathrm{mg} / \mathrm{kg})$ or placebo (saline). Volunteers gave informed consent after the possible adverse consequences (cognitive numbing, extrapyramidal side effects, anhedonia) and their transitory nature as a result of haloperidol was explained. The double-blind pharmacological treatment was administered intravenously at 10 a.m., and 90 min after injection, participants began to work on the visual stimulus association task that lasted about $1 \mathrm{hr}$. The Ethics Committee of the Free University approved this experiment.

The groups did not differ with respect to age (placebo-treated group (PLAC): $34.6 \pm 10.2$ years old; haloperidol-treated group (HAL): $33.8 \pm 11.3$ years old), their scores on the MehrfachwahlWortschatz-Test-B (Multiple-Choice Vocabulary Intelligence Test-B; Lehrl, 1977; $\mathrm{IQ}_{\mathrm{PLAC}}=126 \pm 10, \mathrm{IQ}_{\mathrm{HAL}}=117 \pm 15 ; t(22)=1.8$, n.s.), on the Leistungsprüfsystem 2 (Achievement Measure System 2; Horn, 1983; $\mathrm{IQ}_{\mathrm{PLAC}}=115 \pm 11, \mathrm{IQ}_{\mathrm{HAL}}=113 \pm 17$; $t(22)=0.3$, n.s.), or on the Lern- und Gedächtnistest 3 (Learning and Memory Test 3; Bäumler, 1974; percent correct PLAC $=46 \pm$ $18 \%$, percent correct $_{\mathrm{HAL}}=50 \pm 18 \% ; t(22)=-0.5$, n.s.). The mean handedness score (Oldfield, 1971) did not differ between groups $\left(\right.$ handedness PLAC $=73 \pm 22$, handedness $_{\mathrm{HAL}}=71 \pm 19$; $t(22)=0.5$, n.s.). All participants reported normal or corrected- to-normal vision. They denied prior history of psychosis, psychiatric illness, organic brain disease, severe cognitive impairment, or recent drug or alcohol intoxication. All participants underwent the structured clinical diagnostic interview (SCID; German adaptation: Wittchen et al., 1997) to screen them for Axis I disorders. Participants were paid for participation (DM 100).

\section{Stimuli and Procedure}

The stimuli and procedures were identical to the working-memorydependent trace version of the probabilistic association task of Experiment 1.

\section{Electrophysiological Recording and ERP Analysis}

The electrophysiological recording and ERP analysis were identical to Experiment 1.

\section{Results}

\section{Contingency Judgments}

The contingency judgments that were obtained across three blocks of training in each validity condition (low, high cue1 validity) were analyzed. A 2 (Treatment) $\times 2$ (Cue1 Validity) ANOVA was computed using the cue 1 contingency ratings. A significant main effect of cue 1 validity emerged, $F(1,22)=35.7, p<.05$, and no other effects were significant. Thus, the cue 1 contingency ratings of both subject groups similarly reflected the validity manipulation.

As revealed by Figure 5 (left panel), the cue 2 contingency ratings of placebo-treated individuals for the high cuel validity condition exceeded that for the low cue 1 validity condition, reflecting a trend towards cooperative cue interaction. However, the treatment with haloperidol gave rise to a trend towards competitive interaction between the cues because their cue 2 contingency ratings for the low cue 1 validity condition exceeded that for the high cue1 validity condition.

Statistical tests supported the differential cue interaction effect observed in placebo- and haloperidol-treated individuals. A 2 (Treatment) $\times 2$ (Cue1 Validity) ANOVA was computed using the cue 2 contingency ratings. The presence of a differential cue interaction effect was confirmed by a significant Treatment $\times$ Validity interaction effect, $F(1,22)=5.6, p<.05$. The group difference tended
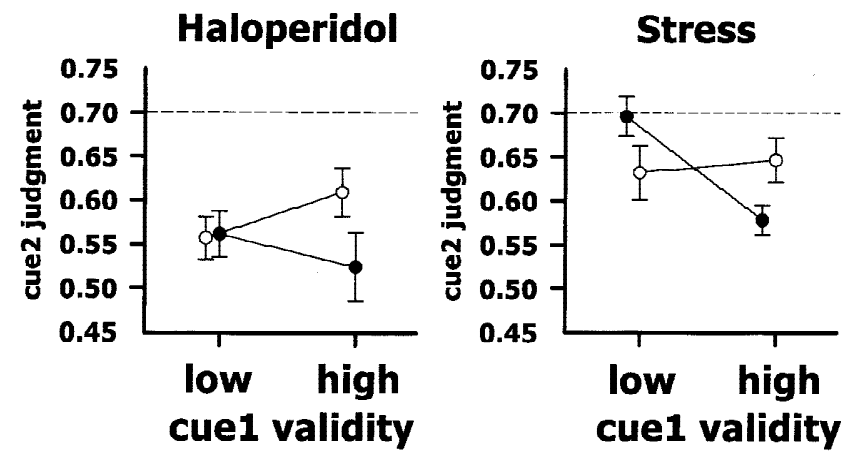

Figure 5. Mean contingency judgments for cue 2 as a function of the validity of cue1 after completion of training. Left panel: Judgments obtained in the trace version of the probabilistic association task (Experiment 2), with placebo-treated (open symbols) and haloperidol-treated (filled symbols) individuals. Right panel: Judgments obtained from the standard trace version of the probabilistic association task (filled symbols) and under the application of a mild stressor (open symbols). 
towards statistical reliability in the high validity condition, $t(22)=$ $1.8, p<.10$, placebo-treated $>$ haloperidol-treated, but not in the low validity condition, $t(22)=-0.1$, n.s., placebo-treated $=$ haloperidol-treated.

\section{Cue ERPs}

Both types of cues (letters, numbers) elicited a broadly distributed frontal P150 with inverted polarity at occipito-temporal sites (N150). Figure 6 shows grand-average ERP waveforms elicited by cue1, separated for placebo-treated (thin lines) and haloperidol-treated (thick lines) subjects. The N150 at occipito-temporal electrodes obtained in response to cue1 (letters) peaked at a latency of $162 \mathrm{~ms}$ with a mean amplitude of $-4.0 \mu \mathrm{V}$. An ANOVA (Treatment $\times$ Validity $\times$ Site $\times$ Hemisphere) confirmed a significant Treatment $\times$ Hemisphere effect for the $\mathrm{N} 150$ amplitude, $F(1,22)=4.3$, $p<.05$. No other main or interaction effect reached significance, except Site $\times$ Hemisphere, $F(1,22)=5.2, p<.05$. Post hoc comparisons at the two temporal sites $(\mathrm{T} 5, \mathrm{~T} 6)$ revealed that the augmentation of the N150 amplitude in haloperidol-treated subjects was confined to the right hemisphere, $t(22)=-2.3, p<.05$, with no significant augmentation in the left hemisphere, $t(22)=$ $0.2 \mathrm{~ms}$. For the N150 latency, no main or interaction effect reached significance, all $F$ 's $(1,22)<3.8$.

The frontal P150 peaked at a latency of $178 \mathrm{~ms}$ with an amplitude of $6.4 \mu \mathrm{V}$. Neither the P150 amplitude nor the P150 latency was influenced by treatment, validity, or the interaction Treatment $\times$ Validity, amplitude: all $F$ 's $(1,22)<1.6$, latency: all $F$ 's $(1,22)<1.8$.

A very similar pattern of results emerged for the ERPs elicited by cue2 (numbers). The N150 at the preselected occipito-temporal electrodes peaked at a latency of $162 \mathrm{~ms}$ with a mean amplitude of $-4.1 \mu \mathrm{V}$. An ANOVA (Treatment $\times$ Validity $\times$ Site $\times$ Hemisphere) confirmed a significant Treatment $\times$ Hemisphere effect for the N150 amplitude, $F(1,22)=4.6, p<.05$. Post hoc comparisons at the two temporal sites (T5, T6) revealed that the augmentation of the N150 amplitude in haloperidol-treated subjects seemed to be confined to the right hemisphere, $t(22)=-1.8, p<.10$, with no significant augmentation in the left hemisphere, $t(22)=0.15 \mathrm{~ms}$. In addition, other main (validity, $F(1,22)=6.9, p<.05$; site, $F(1,22)=8.7, p<.05$; hemisphere, $F(1,22)=18.7, p<.05)$ and interaction (Site $\times$ Hemisphere, $F(1,22)=5.2, p<.05)$ effects reached significance. For the N150 latency, no main or interaction effect reached significance, all $F$ 's $(1,22)<0.7$.

The frontal P150 peaked at a latency of $187 \mathrm{~ms}$ with an amplitude of $6.7 \mu \mathrm{V}$. Neither the P150 amplitude nor the P150 latency was influenced by treatment, validity, or the interaction Treatment $\times$ Validity, amplitude: all $F$ 's $(1,22)<1.8$, latency: all $F$ 's $(1,22)<1.3$.

\section{Outcome ERPs}

The ERPs elicited by outcomes are presented in Figure 7. As in Experiment 1, the ERP analysis was restricted to the low validity condition.

The N2/P3 complex obtained from placebo-treated and haloperidol-treated subjects revealed somewhat attenuated ERP components in haloperidol-treated subjects. For example, the P3 peak amplitude at $\mathrm{Pz}$ was attenuated in haloperidol-treated as compared to placebo-treated subjects, $t(22)=2.2, p<.05$. For the N2, an ANOVA (Treatment $\times$ Correctness $\times$ Site) was performed. Correctness, $F(1,22)=9.1, p<.05$; and site, $F(2,44)=27.6, p<$ $.05, \epsilon=.72$, proved significant. The main effect of treatment reached significance, $F(1,22)=5.3, p<.05$, with haloperidol-

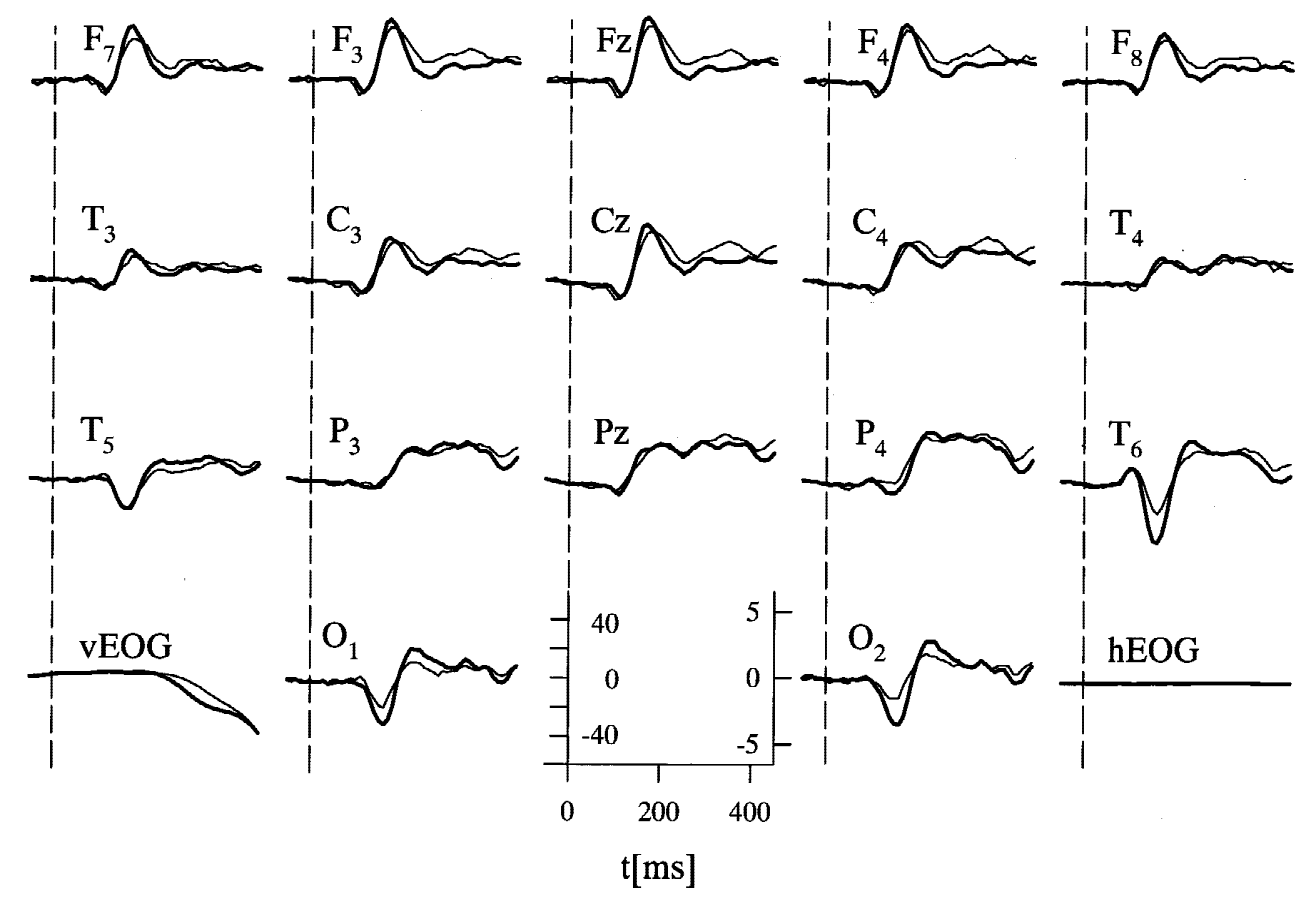

Figure 6. Grand-average ERPs elicited by cue1 (letter) from -50 to $400 \mathrm{~ms}$, averaged across both validity conditions. Thin (thick) line: ERPs recorded from placebo- (haloperidol-) treated subjects. $\mathrm{Fz}, \mathrm{Cz}$, and $\mathrm{Pz}$ refer to midline frontal, central, and parietal sites, respectively. F3, C3, P3, T5, and O1 refer to left frontal, central, parietal, temporal, and occipital sites, respectively. F4, C4, P4, T6, and $\mathrm{O} 2$ refer to right frontal, central, parietal, temporal, and occipital sites, respectively. 


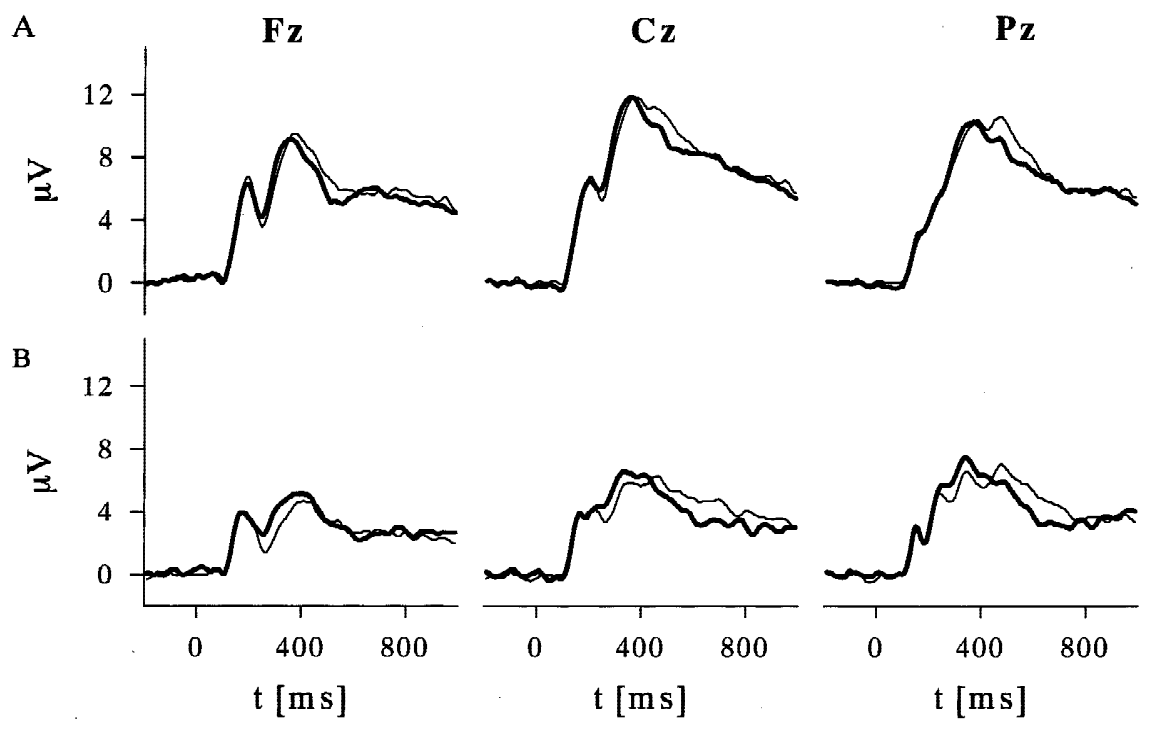

Figure 7. Grand-average ERPs elicited by outcome stimuli from -100 to $1,000 \mathrm{~ms}$ obtained from the low validity condition. (a) ERPs recorded from placebo-treated subjects. (b) ERPs recorded from haloperidol-treated subjects. Thin (thick) line: ERPs recorded from outcome stimuli that disconfirmed (confirmed) the outcome expectation. $\mathrm{Fz}, \mathrm{Cz}$, and $\mathrm{Pz}$ refer to midline frontal, central, and parietal sites, respectively. treated subjects displaying a somewhat attenuated N2 mean amplitude, whereas the interaction effects involving treatment were not significant, all $F$ 's $<3.0$.

Correctness influenced the P3 significantly, $F(1,22)=8.0, p<$ .05 . The main effect of treatment reached significance, $F(1,22)=$ $6.4, p<.05$, with haloperidol-treated subjects displaying a somewhat attenuated P3 mean amplitude. The interaction effect (Treatment $\times$ Correctness) did not reach significance, $F(1,22)<1.7$.

\section{Discussion}

The amplitude of the occipito-temporal N150, but not the amplitude of the fronto-central P150, was specifically augmented by the acute administration of haloperidol. Thus, the amplitude of the occipito-temporal N150 seems to be modulated by D2 dopamine receptors: Overstimulation of this receptor in conditions of excess levels of endogenous dopamine (such as schizotypy) might attenuate the amplitude of the occipito-temporal N150 (Experiment 1) and the (partial) blockade of these receptors might augment the N150 amplitude. The modulation of the N150 amplitude was largely confined to the right hemisphere.

The placebo group did not show evidence for selective associative learning in this working-memory-dependent trace version of the probabilistic association task. This finding is in sharp contrast to the results that we obtained elsewhere (Kopp \& Reischies, 2000; Kopp \& Wolff, 2000; Experiment 1) from healthy subjects. Instead, it resembles the results obtained from schizophrenic patients (Kopp \& Reischies, 2000) and psychometrically identified schizotypal individuals (Experiment 1). This loss of workingmemory-dependent selectivity of associative learning in the placebo group may indicate a neurocognitive effect of the stress response to the intravenous administration of a possibly adverse drug (recall, e.g., that the possible adverse effects of haloperidol were explained to all volunteers). In line with this interpretation, the experience of venous catheterization is known to elevate plasma cortisol (Rose \& Hurst, 1975). If venous catheterization (of a potentially adverse drug) actually elicited a stress response, then the verum (haloperidol) counteracted a neurocognitive effect of this stressor, namely the loss of the working-memory-dependent selectivity of associative learning. The experience of a potentially harmful stressor would be among the conditions that lead to an overstimulation of D2 receptors that may be suppressed by haloperidol. Thus, the dopamine receptors would likely mediate these stress-induced neurocognitive alterations (Arnsten, 2000).

Two arguments may be relevant here. First, Hennig, Rzepka, Mai, and Netter (1995) reported that the pretreatment with haloperidol suppressed the hormonal stress response that was associated with the administration of a heat stressor in healthy volunteers. Second, in an additional pilot study, we examined whether the loss of the selectivity of associative learning is among the neurocognitive effects of a mild stressor. Exposure to inescapable electrical shock is often used as a stressor in animal studies designed to examine the effects of stress on learning (e.g., Shors, Weiss, \& Thompson, 1992). We examined the effects of an unavoidable, frequently administered (240 times) mild electrical shock as a stressor in the working-memory-dependent trace version of the probabilistic association task. Thirty-one healthy volunteers (10 men, 21 women; $24.1 \pm 3.4$ years of age) learned to predict the occurrence of a neutral (i.e., the visual symbol \#) or aversive (electrical shock administered by a Toennies shock generator to the hypothenar eminence of the nondominant hand, mean amplitude $7 \mathrm{~mA}$ [range 4-10], duration $10 \mathrm{~ms}$, subjectively rated as distressing, but not painful) outcome, other details of the task being equal to the task that was described above (Experiment 1). The performance of this group of subjects was compared to the performance of another group of 32 healthy young subjects (16 men, 16 women; $25.5 \pm 4.3$ years of age; described in Kopp \& Wolff, 2000; Experiments 1 and 2) who performed the standard version of the task (Experiment 1). The contingency judgments that were obtained after three blocks of training in each validity condition (low, high cue1 validity) were analyzed. A 2 (Group) $\times 2$ (Cue1 Validity) ANOVA was computed using the cue 1 contingency ratings. A significant main effect of cue 1 validity emerged, $F(1,61)=228.0$, $p<.05$, and no other effects were significant. Thus, the cue 1 contingency ratings of both subject groups similarly reflected the validity manipulation. As revealed by Figure 5, right panel, the cue 2 contingency ratings of the shock group for the high cue 1 validity condition (slightly) exceeded that for the low cue1 validity condition after completion of training, reflecting nonselective associative learning. Differential selectivity of associative learning in 
the two groups of subjects was confirmed by a significant Group $\times$ Validity interaction effect, $F(1,61)=8.9, p<.05$. Thus, the application of a mild, but potentially harmful, stressor may actually lead to a loss of the working-memory-dependent selectivity of associative learning.

Haloperidol often shows a tendency to impair cognitive performance (e.g., Beuzen, Taylor, Wesnes, \& Wood, 1999; Legangneux et al., 2000) and to reduce EEG indices of cortical arousal (e.g., McClelland, Cooper, \& Pilgrim, 1990) at doses comparable to the dose that was used in this study $(0.04 \mathrm{mg} / \mathrm{kg})$. At lower doses of haloperidol, Williams et al. (1997) reported enhanced latent inhibition in visual tasks in healthy people. Although the relationship between latent inhibition and working-memorydependent selective associative learning remains to be delineated, similar mechanisms of action may underlie these two types of haloperidol-induced improvement of cognitive functioning. Effects of haloperidol on ERPs have less often been described (but see Ford et al., 1994). Our results suggest augmenting effects of haloperidol on earlier (N150, but not P150) and attenuating effects on later (P3) components of the ERP. A similar dissociation of effects of sulpiride, a selective D2 dopamine receptor antagonist, was described by Antal, Keri, and Bodis-Wollner (1997) for early and late components of visual ERPs that were recorded from monkeys.

The pharmacological specificity of the postulated relevant mechanism of action of haloperidol (i.e., the blockade of D2 dopamine receptor) requires additional research. This is necessary because haloperidol is known to bind with high affinity to sigma opioid receptors, and with lower affinity at alpha-adrenergic, serotonergic, histaminergic, and muscarinic-cholinergic sites (Seeman, 1990). Thus, the present results might also reflect the binding of haloperidol at nondopaminergic sites in D2 dopamine receptor-poor areas of cerebral cortex. Finally, although haloperidol binds with higher affinity at D2 receptors than at D1 receptors, the possibility needs to be ruled out by appropriate research that the present results reflect the blockade of D1 dopamine receptors.

\section{General Discussion}

The findings reported here can be summarized as follows: Schizotypy (Experiment 1) and the experience of a mild stressor (Experiment 2) seem to be associated with a loss of the working-memorydependent selectivity of associative learning and with attenuated amplitudes of the occipito-temporal N150. The brain dopamine systems, and probably more specifically the family of D2 dopamine receptors, seem to be involved in the modulation of these effects because both abnormalities were reversed by administration of a single dose of haloperidol (Experiment 2). These findings suggest that the experience of stress may intensify the workingmemory-dependent associative loosening that itself may be the fundamental cognitive symptom in the schizophrenia spectrum.

As already discussed, the dopamine D1 receptor is preferentially involved in the modulation of working memory performance (Müller et al., 1998; Sawaguchi \& Goldman-Rakic, 1991). However, the role of the dopamine D2 receptor for working memory still needs to be specified. Prefrontal cortical microcircuits are modulated either by dopamine receptors on glutamatergic pyramidal cells or on gamma-aminobutyric (GABA) interneurons. Seamans, Gorelova, Durstewitz, and Yang (2001) recently characterized the effects of dopamine on GABAergic inputs to prefrontal pyramidal neurons in vitro. Dopamine had a temporally biphasic effect on evoked inhibitory postsynaptic potentials: Although an initial abrupt reduction was mediated by D2 receptors, a late, slower developing enhancement was mediated by D1 receptors. When D2 modulation dominates, there is a net reduction in local inhibition and multiple representations can be held in prefrontal cortical networks. When D1 modulation dominates, there is a net increase in local inhibition, and inputs have difficulty accessing prefrontal networks with the exception of particularly strong inputs. Thus, overstimulation of D2 receptors and/or understimulation of D1 receptors (i.e., D2-dominated states) seem to be associated with a decrease in the competitive dynamics of prefrontal cortical microcircuits that might express itself as a loss of prioritization of predictive information in working memory.

However, working memory depends on interactions between the prefrontal cortex and cortical association areas (e.g., Ungerleider, Courtney, \& Haxby, 1998). For example, Desimone (1996) described neuronal responses sampled from inferior temporal (IT) cortex (which is the putative origin of the N150) of monkeys in memory-demanding tasks. In a delayed-matching-tosample task, some neurons in the IT cortex enhanced their firing when the stimulus matched the sample, but not when the stimulus matched a task-irrelevant stimulus. This suggests that the content of the memory set can determine which stimulus is attended to in the visual field. According to this analysis, the attenuated N150 in high schizotypal individuals might be set related, that is, it might occur secondary to deficient prioritization of information in the central executive system of working memory (top-down model). Alternatively, deficient encoding into the sensory (Javitt et al., 1997; Knight, 1994) or into the episodic buffer might itself be responsible for defective prioritization in the central executive system of working memory (bottom-up model). Thus, decreased selectivity of prefrontal cortical microcircuits in D2-dominated states does not necessarily reflect the essential aspects of the pathophysiology in the schizophrenia spectrum (e.g., Laroche, Davis, \& Jay, 2000).

\section{REFERENCES}

Abi-Dargham, A., Rodenhiser, J., Printz, D., Zea-Ponce, Y., Gil, R., Kegeles, L. S., Weiss, R., Cooper, T. B., Mann, J. J., Van Heertum, R. L., Gorman, J. M., \& Laruelle, M. (2000). Increased baseline occupancy of D2 receptors by dopamine in schizophrenia. Proceedings of the $\mathrm{Na}$ tional Academy of Sciences USA, 97, 8104-8109.

American Psychiatric Association. (1994). Diagnostic and statistical manual of mental disorders (4th revised ed.). Washington, DC: Author.

Antal, A., Keri, S., \& Bodis-Wollner, I. (1997). Dopamine D2 receptor blockade alters the primary and cognitive components of visual evoked potentials in the monkey, Macaca fascicularis. Neuroscience Letters, 232, 179-181.

Arnsten, A. F. (2000). Stress impaired prefrontal cortical function in rats and monkeys: Role of dopamine D1 and norepinephrine alpha-1 receptor mechanisms. Progress in Brain Research, 126, 183-192.

Awh, E., \& Jonides, J. (2001). Overlapping mechanisms of attention and spatial working memory. Trends in Cognitive Science, 5, 119-126.

Baddeley, A. D. (2000). The episodic buffer in working memory. Trends in Cognitive Sciences, 4, 417-422.

Baddeley, A. D., \& Hitch, G. J. (1974). Working memory. In G. A. Bower (Ed.), The psychology of learning and motivation (pp. 47-89). New York: Academic Press.

Bäumler, G. (1974). Lern- und Gedächtnistest 3. [Learning and Memory Test 3.] Göttingen: Hogrefe.

Benes, F. M. (1997). The role of stress and dopamine-GABA interactions 
in the vulnerability for schizophrenia. Journal of Psychiatric Research, 31, 257-275.

Bentin, S., Allison, T., Puce, A., Perez, E., \& McCarthy, G. (1996). Electrophysiological studies of face perceptions in humans. Journal of Cognitive Neuroscience, 8, 551-565.

Berg, P. (1986). The residual after correcting event-related potentials for blink artifacts. Psychophysiology, 23, 354-364.

Beuzen, J. N., Taylor, N., Wesnes, K., \& Wood, A. (1999). A comparison of the effects of olanzapine, haloperidol and placebo on cognitive and psychomotor functions in healthy elderly volunteers. Journal of Psychopharmacology, 13, 152-158.

Bleuler, E. (1911). Dementia praecox or the group of schizophrenias. Translated by J. Zinkin (1950). New York, NY: International Universities Press.

Braver, T. S., Barch, D. M., \& Cohen, J. D. (1999). Cognition and control in schizophrenia: A computational model of dopamine and prefrontal function. Biological Psychiatry, 46, 312-328.

Brebion, G., Amador, X., Smith, M. J., \& Gorman, J. M. (1997). Mechanisms underlying memory impairment in schizophrenia. Psychological Medicine, 27, 383-393.

Bruder, G., Kayser, J., Tenke, C., Rabinowicz, E., Friedman, M., Amador, X., Sharif, Z., \& Gorman, J. (1998). The time course of visuospatial processing deficits in schizophrenia: An event-related brain potential study. Journal of Abnormal Psychology, 107, 399-411.

Carlsson, A. (1987). The dopamine hypothesis of schizophrenia 20 years later. In H. Häfner, W. F. Gattaz, \& W. Janzarik (Eds.), Search for the causes of schizophrenia (pp. 223-235). Berlin: Springer.

Chapman, L. J., \& Chapman, J. P. (2001). Commentary on two articles concerning generalized and specific cognitive deficits. Journal of $A b$ normal Psychology, 110, 31-39.

Chapman, J. P., Chapman, L. J., \& Kwapil, T. R. (1995). Scales for the assessment of schizotypy. In A. Raine, T. Lencz \& S. A. Mednick (Eds.), Schizotypal personality (pp. 79-106). Cambridge: Cambridge University Press.

Chapman, J. P., Chapman, L. J., Kwapil, T. R., Eckblad, M., \& Zinser, M. C. (1994). Putatively psychosis prone subjects 10 years later. Journal of Abnormal Psychology, 103, 171-183.

Claridge, G. (1997). Schizotypy. Oxford: Oxford University Press.

Clark, R. E., \& Squire, L. R. (1998). Classical conditioning and brain systems: The role of awareness. Science, 280, 77-81.

Coull, J. T. (1998). Neural correlates of attention and arousal: Insights from electrophysiology, functional neuroimaging and psychopharmacology. Progress in Neurobiology, 55, 343-361.

Crider, A., Solomon, P. R., \& McMahon, M. A. (1982). Disruption of selective attention in the rat following chronic d-amphetamine administration: Relationship to schizophrenic attention disorder. Biological Psychiatry, 17, 351-361.

de Fockert, J. W., Rees, G., Frith, C. D., \& Lavie, N. (2001). The role of working memory in visual selective attention. Science, 291, 1803-1806.

Desimone, R. (1996). Neural mechanisms for visual memory and their role in attention. Proceedings of the National Academy of Sciences USA, 93, 13494-13499.

Donchin, E., \& Coles, M. G. H. (1988). Is the P300 component a manifestation of context updating? Behavioral and Brain Sciences, 11, 355-372.

Downing, P. E. (2000). Interactions between visual working memory and selective attention. Psychological Science, 11, 467-473.

Fernandes, L. O. L., Keller, J., Giese-Davis, J. E., Hicks, B. D., Klein, D. N., \& Miller, G. (1999). Converging evidence for a cognitive anomaly in early psychopathology. Psychophysiology, 36, 511-521.

Ford, J. M., White, P. M., Csernansky, J. G., Faustman, W. O., Roth, W. T., \& Pfefferbaum, A. (1994). ERPs in schizophrenia: Effects of antipsychotic medication. Biological Psychiatry, 36, 153-170.

Gold, J. M., Rehkemper, G., Binks, S. W., 3rd, Carpenter, C. J., Fleming, K., Goldberg, T. E., \& Weinberger, D. R. (2000). Learning and forgetting in schizophrenia. Journal of Abnormal Psychology, 109, 534-538.

Goldman-Rakic, P. S., \& Selemon, L. D. (1997). Functional and anatomical aspects of prefrontal pathology in schizophrenia. Schizophrenia Bulletin, 23, 437-458.

Gray, N. S., Pickering, A. D., Gray, J. A., Jones, S. H., Abrahams, S., \& Hemsley, D. R. (1997). Kamin blocking is not disrupted by amphetamine in human subjects. Journal of Psychopharmacology, 11, 301311.

Hennig, J., Rzepka, U., Mai, B., \& Netter, P. (1995). Suppression of HPA-axis activity by haloperidol after experimentally induced heat stress. Progress in Neuropsychopharmacology and Biological Psychiatry, 19, 603-614.

Hillyard, S. A., \& Picton, T. W. (1987). Electrophysiology of cognition. In F. Plum (Ed.), Handbook of physiology: Sec 1. The nervous system (Vol. V, Part 2, pp. 519-584). Bethesda, MD: American Physiological Society.

Hillyard, S. A., Teder-Sälejärvi, W. A., \& Münte, T. F. (1998). Temporal dynamics of early perceptual processing. Current Opinion in Neurobiology, 8, 202-210.

Horn, W. (1983). Leistungsprüfsystem 2. [Achievement Measure System 2.] Göttingen: Hogrefe.

Javitt, D. C., Strous, R. D., Grochowski, S., Ritter, W., \& Cowan, N. (1997). Impaired precision, but normal retention, of auditory sensory ("echoic") memory information in schizophrenia. Journal of Abnormal Psychology, 106, 315-324.

Jeffreys, D. A. (1996). Evoked potential studies of face and object processing. Visual Cognition, 3, 1-38.

Jones, S. H., Gray, J. A., \& Hemsley, D. R. (1990). The Kamin blocking effect, incidental learning and psychoticism. British Journal of Psychology, 81, 95-110.

Jones, S. H., Gray, J. A., \& Hemsley, D. R. (1992). Loss of the Kamin blocking effect in acute but not chronic schizophrenics. Biological Psychiatry, 32, 739-755.

Jones, S. H., Hemsley, D. R., Ball, S., \& Serra, A. (1997). Disruption of the Kamin blocking effect in schizophrenia and in normal subjects following amphetamine. Behavioural Brain Research, 88, 103-114.

Kamin, L. J. (1969). Selective association and conditioning. In N. J. Mackintosh \& W. K. Honig (Eds.), Fundamental issues in associative learning (pp. 42-64). Halifax, NS: Dalhousie University Press.

Klein, C., Andresen, B., \& Jahn, T. (1997). Erfassung der schizotypen Persönlichkeit nach DSM-III-R. Diagnostica, 43, 347-369.

Knight, R. A. (1983). Converging models of cognitive deficit in schizophrenia. In W. D. Spaulding \& J. D. Cole (Eds.), Nebraska symposium on motivation, Vol. 31: Theories of schizophrenia and psychosis (pp. 93156). Lincoln, NE: University of Nebraska Press.

Knight, R. A. (1994). Comparing cognitive models of schizophrenics input dysfunction. In R. L. Cromwell \& C. R. Snyder (Eds.), Schizophrenia. Origins, processes, treatment, and outcome (pp. 151-175). New York, NY: Oxford University Press.

Kopp, B., \& Reischies, F. M. (2000). Experimental evidence for distorted associative memory in chronic schizophrenic patients. Cognitive Neuropsychiatry, 5, 241-254.

Kopp, B., \& Wolff, M. (2000). Brain mechanisms of selective learning: Event-related potentials provide evidence for error-driven learning in humans. Biological Psychology, 51, 223-246.

Kruschke, J. K., \& Johansen, M. K. (1999). A model of probabilistic category learning. Journal of Experimental Psychology: Learning, Memory, and Cognition, 25, 1083-1119.

Kwapil, J. K., Miller, M. B., Zinser, M. C., Chapman, J. P., \& Chapman, L. J. (1997). Magical ideation and social anhedonia as predictors of psychosis proneness: A partial replication. Journal of Abnormal Psychology, 106, 491-495.

Laroche, S., Davis, S., \& Jay, T. M. (2000). Plasticity at hippocampal to prefrontal cortex synapses: Dual roles in working memory and consolidation. Hippocampus, 10, 438-446.

Legangneux, E., McEwen, J., Wesnes, K. A., Bergougnan, L., Miget, N., Canal, M., L'Heritier, C., Pinquier, J. L., \& Rosenzweig, P. (2000). The acute effects of amisulpride (50 $\mathrm{mg}$ and $200 \mathrm{mg}$ ) and haloperidol (2 mg) on cognitive function in healthy elderly volunteers. Journal of Psychopharmacology, 14, 164-171.

Lehrl, S. (1977). Mehrfachwahl-Wortschatz-Test-B. [Multiple-Choice Vocabulary Intelligence Test-B.] Erlangen: Straube.

Luck, S. J., Woodman, G. F., \& Vogel, E. K. (2000). Event-related potential studies of attention. Trends in Cognitive Sciences, 4, 432-440.

Mackintosh, N. J. (1975). A theory of attention: Variations in the associability of stimuli with reinforcement. Psychological Review, 82, 276-298.

McClelland, G. R., Cooper, S. M., \& Pilgrim, A. J. (1990). A comparison of the central nervous system effects of haloperidol, chlorpromazine and sulpiride in normal volunteers. British Journal of Clinical Pharmacology, 30, 795-803.

McElree, B. (2001). Working memory and focal attention. Journal of Experimental Psychology: Learning, Memory, and Cognition, 27, 817-835.

Meehl, P. E. (1990). Toward an integrated theory of schizotaxia, schizotypy, schizophrenia. Journal of Personality Disorders, 4, 1-99. 
Miller, R. R., \& Matute, H. (1996). Biological significance in forward and backward blocking: Resolution of a discrepancy between animal conditioning and human causal judgment. Journal of Experimental Psychology: General, 125, 370-386.

Müller, U., von Cramon, D. Y., \& Pollmann, S. (1998). D1- versus D2receptor modulation of visuospatial working memory in humans. Journal of Neuroscience, 18, 2720-2728.

Oades, R. D., Zimmermann, B., \& Eggers, C. (1996). Conditioned blocking in patients with paranoid, non-paranoid psychosis or obsessive compulsive disorder: Associations with symptoms, personality and monoamine metabolism. Journal of Psychiatric Research, 30, 369-390.

Oldfield, R. C. (1971). The assessment and analysis of handedness: The Edinburgh Inventory. Neuropsychologia, 9, 97-113.

Park, S., \& Holzman, P. S. (1992). Schizophrenics show spatial working memory deficits. Archives of General Psychiatry, 49, 975-982.

Peroutka, S. J., \& Snyder, S. H. (1980). Relationship of neuroleptic drug effects at brain dopamine, serotonin, alpha-adrenergic, and histamine receptors to clinical potency. American Journal of Psychiatry, 137, $1518-1522$.

Perry, W., Heaton, R. K., Potterat, E., Roebuck, T., Minassian, A., \& Braff, D. L. (2001). Working memory in schizophrenia: Transient "online" storage versus executive functioning. Schizophrenia Bulletin, 27, 157-176.

Price, P. C., \& Yates, J. F. (1993). Judgmental overshadowing: Further evidence of cue interaction in contingency judgment. Memory \& Cognition, 21, 561-572.

Price, P. C., \& Yates, J. F. (1995). Associative and rule-based accounts of cue interaction in contingency judgment. Journal of Experimental Psychology: Learning, Memory, and Cognition, 21, 1639-1655.

Raine, A. (1991). The Schizotypal Personality Questionnaire (SPQ): A scale for the assessment of schizotypal personality based on DSM-III-R criteria. Schizophrenia Bulletin, 17, 555-564.

Raine, A., Lencz, T., \& Mednick, S. A. (1995). Schizotypal personality. Cambridge: Cambridge University Press.

Raine, A., Reynolds, C., Lencz, T., \& Scerbo, A. (1994). Cognitive/ perceptual, interpersonal and disorganized features of schizotypal personality. Schizophrenia Bulletin, 20, 191-201.

Rescorla, R., \& Wagner, A. R. (1972). A theory of Pavlovian conditioning: Variations in the effectiveness of reinforcement and nonreinforcement. In A. Black \& W. Prokasy (Eds.), Classical conditioning II: Current research and theory (pp. 64-99). New York, NY: Appleton-CenturyCrofts.

Roitman, S. E., Mitropoulou, V., Keefe, R. S., Silverman, J. M., Serby, M., Harvey, P. D., Reynolds, D. A., Mohs, R. C., \& Siever, L. J. (2000). Visuospatial working memory in schizotypal personality disorder patients. Schizophrenia Research, 14, 447-455.

Rose, R. M., \& Hurst, M. W. (1975). Plasma cortisol and growth hormone responses to intravenous catheterization. Journal of Human Stress, 1, 22-36.

Sams, M., Hietanen, J. K., Hari, R., Ilmoniemi, R. J., \& Lounasmaa, O. V. (1997). Face-specific responses from the human inferior occipitotemporal cortex. Neuroscience, 77, 49-55.

Sawaguchi, T., \& Goldman-Rakic, P. S. (1991). D1 dopamine receptors in prefrontal cortex: Involvement in working memory. Science, 251, 947-950.

Schendan, H. E., Ganis, G., \& Kutas, M. (1998). Neurophysiological evidence for visual perceptual categorization of words and faces within 150 ms. Psychophysiology, 35, 240-251.
Seamans, J. K., Gorelova, N., Durstewitz, D., \& Yang, C. R. (2001). Bidirectional Dopamine modulation of GABAergic inhibition in prefrontal cortical pyramidal neurons. The Journal of Neuroscience, 21, 3628-3638.

Seeman, P. (1990). Atypical neuroleptics: Role of multiple receptors, endogenous dopamine, and receptor linkage. Acta Psychiatrica Scandinavica Supplementum (Copenhagen), 358, 14-20.

Seeman, P., \& Kapur, S. (2000). Schizophrenia: More dopamine, more D2 receptors. Proceedings of the National Academy of Sciences USA, 97, 7673-7675.

Shanks, D. R., Lopez, F. J., Darby, R. J., \& Dickinson, A. (1996). Distinguishing associative and probabilistic contrast theories of human contingency judgment. In D. R. Shanks, K. J. Holyoak, \& D. L. Medin (Eds.), Causal learning. The psychology of learning and motivation (Vol. 34, pp. 265-311). San Diego: Academic Press.

Shors, T. J., Weiss, C., \& Thompson, R. F. (1992). Stress-induced facilitation of classical conditioning. Science, 257, 537-539.

Siever, L. J., Amin, F., Coccaro, E. F., Bernstein, D., Kavoussi, R. J., Kalus, O., Horvath, T. B., Warne, P., Davidson, M., \& Davis, K. L. (1991) Plasma homovanillic acid in schizotypal personality disorder. American Journal of Psychiatry, 148, 1246-1248.

Siever, L. J., \& Davis, K. L. (1991). A psychobiological perspective on the personality disorders. American Journal of Psychiatry, 148, 1647-1658.

Sommer, W., Schweinberger, S. R., \& Matt, J. (1991). Human brain potential correlates of face encoding into memory. Electroencephalography and Clinical Neurophysiology, 79, 457-463.

Strauss, M. E. (2001). Demonstrating specific cognitive deficits: A psychometric perspective. Journal of Abnormal Psychology, 110, 6-14.

Treisman, A. M., \& Kanwisher, N. G. (1998). Perceiving visually presented objects: Recognition, awareness, and modularity. Current Opinion in Neurobiology, 8, 218-226.

Ungerleider, L. G., Courtney, S. M., \& Haxby, J. V. (1998). A neural system for human visual working memory. Proceedings of the National Academy of Sciences USA, 95, 883-890.

Ungerleider, L. G., \& Mishkin, M. (1982). Two cortical visual systems. In D. J. Ingle (Ed.), Analysis of visual behavior (pp. 549-586). Cambridge, MA: MIT Press

Vogel, E. K., Luck, S. J., \& Shapiro, K. L. (1998). Electrophysiological evidence for a postperceptual locus of suppression during the attentional blink. Journal of Experimental Psychology: Human Perception and Performance, 24, 1636-1674.

Wagner, A. R., Logan, F. A., Haberlandt, K., \& Price, T. (1968). Stimulus selection in animal discrimination learning. Journal of Experimental Psychology, 76, 171-180.

Walker, E. F., \& Diforio, D. (1997). Schizophrenia: A neural diathesisstress model. Psychological Review, 104, 667-685.

Williams, J. H., Wellman, N. A., Geaney, D. P., Feldon, J., Cowen, P. J., \& Rawlins, J. N. (1997). Haloperidol enhances latent inhibition in visual tasks in healthy people. Psychopharmacology (Berlin), 133, 262-268.

Wittchen, H. U., Zaudig, M., \& Fydrich, T. (1997). Strukturiertes Klinisches Interview für DSM-IV. Göttingen: Hogrefe.

(Received August 8, 2000; AcCePted December 6, 2001)

\section{APPENDIX}

Instructions to participants read as follows:

This experiment examines the perception of contingencies between stimuli. Two cues (a letter and a number) are presented in each trial, which are followed by an additional stimulus. The probability of that stimulus being a '\#' or a ' $*$ ' depends upon the cues. After the cues appeared, you have to predict the identity of the outcome stimulus by pressing one of two keys. You can check whether your prediction was correct by comparing the predicted and actual outcome stimuli. Six blocks 80 trials each will follow. The contingencies between cues and outcomes are altered between blocks, but not within blocks. After each block, you will have to rate the extent to which cues and outcomes were related. 